\title{
6 Experimental investigations of the V2-Reconstruction Hypothesis
}

In this chapter, I present four self-paced reading experiments on German that test the predictions of the V2-Reconstruction Hypothesis. The first two experiments make use of a verbal NPI to identify the temporal locus of interpretation. In an environment that does not license NPIs, the interpretation of such an NPI will lead to ungrammaticality which will result in increased reading times. The second experiment, in Section 6.2 is a follow-up study which eliminates potential confounds in the first experiment's design. The third experiment in Section 6.3 makes use of two verb groups that differ in their selectional requirements of infinitives. Violation of the selectional requirements will result in ungrammaticality which indicates the point at which these requirements are evaluated. The fourth experiment in Section 6.4 investigates argument order preferences dependent on the type of verb in the V2-position. The results of the first three experiments confirm the predictions of the V2-Reconstruction Hypothesis. The results of the fourth experiment are compatible with the V2-Reconstruction Hypothesis. Due to the fact that the last experiment does not involve a sharp contrast in grammaticality but only preferences, the results are less clear-cut and the interpretation is less evident.

\subsection{Experiment 2: Reconstruction of the verbal NPI brauchen (self-paced reading)}

In Section 3.3.2, I argued that the licensing of verbal NPIs in German has to be evaluated in their base position. This prediction is put to the test in an experimental setting. First, I summarize findings on correlates of (failed) NPI-licensing that were reported in the literature. Subsequently, I explicate how the rationale of the experiment makes use of those processing effects to evaluate the predictions of the V2-Reconstruction Hypothesis.

Previous research on processing NPIs showed that participants are sensitive to specific licensing condition, as predicted by grammatical accounts. In rating experiments, sentences which lack a licensor, as in (1b) receive comparably low acceptability ratings as do sentences in which the licensor is not in a c-command relation with the NPI, as in (1c) (Saddy et al. 2004, Xiang et al. 2013, Parker \& Phillips 2016, Yanilmaz \& Drury 2018). 
(1) a. Kein ${ }_{\text {LIC }}$ Mann, [der einen Bart hatte,] war jemals ${ }_{\text {NPI }}$ glücklich. no man who a beard had was ever happy

'No man who had a beard was ever happy.'

b. ^Ein Mann, [der einen Bart hatte,] war jemals ${ }_{\mathrm{NPI}}$ glücklich. a man who a beard had was ever happy

‘`A man who had a beard was ever happy.'

c. ^Ein Mann, [der [keinen Bart $]_{\text {LIC }}$ hatte,] war jemals ${ }_{\text {NPI }}$ glücklich. a man who no beard had was ever happy

‘`A man who had no beard was ever happy.'

(Drenhaus et al. 2005: 146)

In on-line processing, participants showed immediate responses to licensing violations directly at the NPI (e.g. jemals). Violations yield prolonged reading times (RTs) for roughly three segments (Vasishth et al. 2008, Xiang et al. 2013, Parker \& Phillips 2016). In ERP-experiments, NPI-licensing violations triggered N400 effects (Saddy et al. 2004, Drenhaus et al. 2005, 2007, Yanilmaz \& Drury 2018) and P600 effects (Drenhaus et al. 2005, 2006, Xiang et al. 2009, Yanilmaz \& Drury 2018). These immediate responses, which seems to be detectable robustly across languages, indicate that participants evaluate the licensing of an NPI as soon as the lexical item is interpreted. However, illusory licensors, such as in (1c) lead to significant deviations: more errors and longer response latencies in speeded acceptability judgments (Drenhaus et al. 2005: 148-149), delayed effects of reading time increase (Parker \& Phillips 2016: 326-327), and a smaller N400 effect (Drenhaus et al. 2005: 155-157).

\subsubsection{Rationale}

Recall from the discussion in Section 3.3.2 that, in cases like (2a), the NPI can only be licensed in its base position and not in the surface position as illustrated in (2b). In order to check the licensing requirements of brauchen 'need to', it has to be reconstructed into its base position.

(2) a. Letztendlich braucht $_{\mathrm{NPI}}$ der Autor den Roman nicht LIC $_{\mathrm{zu} \text { drucken }}$ braucht.

'Finally, the author doesn't have to print the novel.' 




If the verbal NPI appears in the V2-position, it precedes its licensor. Nevertheless, no violation of NPI-licensing becomes apparent. According to the V2-Reconstruction Hypothesis, this is unproblematic because the position in which the V2-verb will be interpreted is its base position. Consequently, we expect that the above mentioned processing effects indicating NPI-licensing failure appear only in the base position of the NPI-verb, namely after the infinitive $z u$ drucken 'to print'. I assume furthermore that the processor has a built-in preference to resolve such a pending dependency between the V2- and the base position as early as possible. For filler-gap dependencies (especially wh-movement), this has been thoroughly demonstrated and is widely accepted as the active filler hypothesis (see Frazier \& Clifton 1989: 95). It builds on experimental evidence which indicates that the processor integrates the filler (displaced element) anticipatorily, i. e. before encountering explicit cues for the formation of the actual dependency. If the next incoming segment reveals that the position that was connected to the filler is filled by a surface element, a reanalysis process takes place. This reanalysis is reflected by increased processing load known as the filled-gap effect (Stowe 1986). Following this insight, the target sentences were extensions of sentences like (2), which provided for two possible positions into which the NPI brauchen could reconstruct, as illustrated in (3). ${ }^{1}$ Both positions, \#1 in (3a) and \#2 in (3b) are licit positions

1 In the non-NPI-reading brauchen could also reconstruct after Roman yielding The author needs the novel. Searching for effects related to this reconstruction, which is, however, not dependent on a specific licensing configuration, would require a different experimental set-up. 
for the NPI because they are verbal positions that are locally c-commanded by the negator nicht.

(3) a. Letztendlich braucht der Autor den Roman nicht zu drucken \#1 finally needs the author the novel not to print braucht ...

b. Letztendlich braucht der Autor den Roman zu drucken \#1 unter Umständen finally needs theauthorthe novel to print eventually nicht zu verbieten \#2 braucht ... not to forbid

If participants insert brauchen automatically in \#1 in (3b), as expected under fillergap parsing, the result is a temporarily ungrammatical structure. ${ }^{2}$ The licensing conditions of the NPI are violated as seen in (4a) below. To measure such a potential effect we constructed control sentences, in which the NPI-verb brauchen was replaced by beschließen 'to decide', which appears in the same syntactic environment, selects $z u$-infinitives and constitutes a plausible replacement in the relevant contexts. Crucially, however, beschließen is not an NPI and therefore yields a grammatical structure if it is inserted in \#1, as illustrated by the contrast between (4a) and (4b). On the other hand, beschließen is fully compatible with negation. The difference between the two verbs can therefore be paraphrased as follows: brauchen is ungrammatical in positions which are not in the scope of a negation whereas beschließen is grammatical whether in the scope of negation or not.

(4) a. * Letztendlich braucht der Autor den Roman zu drucken \#1 ... finally needs the author the novel to print

b. Letztendlich beschließt der Autor den Roman zu drucken \#1 ... finally decides the author the novel to print

\subsubsection{Method}

\subsubsection{Materials}

The material consisted of 32 experimental items interspersed with 35 fillers (20 from a different experiment) resulting in 67 stimuli per participant. The target sentences were preceded by a context sentence, as in (5), which introduced the agents

2 To be sure, there is no reason for the parser to hypothesize more than the minimally converging structure; this excludes the expectation of a converging structure that leads to the successful gap filling at \#2. 
and the scene of the item in order to render the target sentences more plausible and to reduce the number of accommodations that have to be made during the reading of the target sentence. The context sentences were not matched for length. The target sentences varied in a $2 \times 2 \times 2$ design with the factors MATRIX.VERB, ILLUSORY.NEG, and LICENSING.NEG, which will be explicated hereafter. The finite matrix verb was either the modal NPI-verb brauchen 'need to', as in (6) or the polarity-neutral verb beschließen 'decide', as in (7). The factorial combination of the two negation positions results in four different negation patterns, which are first illustrated for the +NPI condition in (6): double negation (6a), only the late negation (6b), only the early negation (6c), and no negation at all (6d). Actually, only the second negation is relevant for the licensing of the NPI brauchen in the final structure, hence the term licensing negation. The first negation only appears to be relevant for the licensing of the NPI in the incomplete initial substring. In the final structure, however, the first negation is irrelevant for the licensing configuration because it does not c-command the head of the matrix clause VP/IP, hence the term illusory negation. Therefore the -LICENSOR.NEG conditions in (6c) and (6d) are finally ungrammatical which, however, does not affect measures at earlier points. The same negation patterns occur also with the -NPI verb in (7) with the difference that all four variants are grammatical.

The finite verb was followed by a subject DP and an object DP which were definite masculine singular and therefore unambiguously case marked. Between the two infinitives, i. e. following the first reconstruction site \#1, a 2-word adverbial phrase such as unter Umständen 'possibly' was inserted to obtain a spillover region providing measure points for potential effects of the reconstruction of the finite verb. Similarly the second infinitive, i. e. the second reconstruction site \#2, was followed by a 6-word infinitival clause introduced by the complementizer um 'for'. The potential reconstruction sites (\#1 and \#2) are indicated in the materials below only for illustrational purposes and to facilitate the comparison with the examples of the rationale-section above. These marking were not visible in the materials as they were presented to the participants. Half of the items were followed by a yes/no-comprehension question, as in (8), to evaluate whether participants paid attention to the task. All experimental items are given in the online appendix.

(5) Context:

Ein Autor hat wegen seines neuen Romans Ärger mit seinem Verlag. Er bespricht mit seinem Anwalt, ob er den Druck untersagen soll.

'An author has trouble with his publisher because of his new novel. He talks to his lawyer whether he should forbid the printing.' 
(6) a. +NPI +ILLUSORY.NEG +LICENSOR.NEG

Letztendlich braucht der Autor den Roman nicht zu drucken \#1 unter finally NPI the author the novel not to print under Umständen nicht $\mathrm{zu}$ verbieten \#2, um das mediale Interesse $\mathrm{zu}$ circumstances not to forbid for the medial interest to wecken.

arouse

'Thus the author doesn't have to forbid to not print the novel this time in order to arouse the attention of the media.'

b. +NPI -ILLUSORY.NEG +LICENSOR.NEG

Letztendlich braucht der Autor den Roman zu drucken \#1 unter finally NPI the author the novel to print under Umständen nicht $\mathrm{zu}$ verbieten \#2, um das mediale Interesse $\mathrm{zu}$ circumstances not to forbid for the medial interest to wecken.

arouse

'Thus the author doesn't have to forbid to print the novel this time in order to arouse the attention of the media.'

c. +NPI +ILLUSORY.NEG -LICENSOR.NEG

*Letztendlich braucht der Autor den Roman nicht zu drucken \#1 unter finally NPI the author the novel not to print under Umständen $\mathrm{zu}$ verbieten \#2, um das mediale Interesse zu wecken. circumstances to forbid for the medial interest to arouse

d. +NPI -ILLUSORY.NEG-LICENSOR.NEG

*Letztendlich braucht der Autor den Roman zu drucken \#1 unter finally NPI the author the novel to print under Umständen $\mathrm{zu}$ verbieten \#2, um das mediale Interesse zu wecken. circumstances to forbid for the medial interest to arouse

(7) a. -NPI +ILLUSORY.NEG + LICENSOR.NEG

Letztendlich beschließt der Autor den Roman nicht zu drucken \#1 finally decides the author the novel not to print unter Umständen nicht zu verbieten \#2, um das mediale Interesse under circumstances not to forbid for the medial interest $\mathrm{zu}$ wecken.

to arouse

'Thus the author decides not to forbid to not print the novel this time in order to arouse the attention of the media.' 
b. -NPI -ILLUSORY.NEG +LICENSOR.NEG

Letztendlich beschließt der Autor den Roman zu drucken \#1 unter Umständen nicht zu verbieten \#2, um das mediale Interesse zu wecken.

'Thus the author decides not to forbid to print the novel this time in order to arouse the attention of the media.'

c. -NPI +ILLUSORY.NEG - LICENSOR.NEG

Letztendlich beschließt der Autor den Roman nicht zu drucken \#1 unter Umständen zu verbieten \#2, um das mediale Interesse zu wecken.

'Thus the author decides to forbid to not print the novel this time in order to arouse the attention of the media.'

d. -NPI -ILLUSORY.NEG -LICENSOR.NEG

Letztendlich beschließt der Autor den Roman zu drucken \#1 unter Umständen $\mathrm{zu}$ verbieten \#2, um das mediale Interesse zu wecken.

'Thus the author decides to forbid to print the novel this time in order to arouse the attention of the media.'

(8) COMPREHENSION QUESTION:

Hat der Autor mit seinem Anwalt gesprochen?

'Did the author talk to his lawyer'

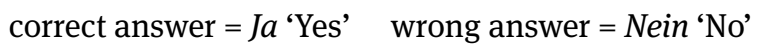

\subsubsection{Predictions}

The predictions are as follows: Because reconstruction of the finite verb is an automated process, the finite verb will always be reconstructed into the earliest syntactically possible position. Consequently, longer reading times are predicted from \#1 onwards, i. e. drucken, in the +NPI, -ILLUSORY.NEG-condition, in which an NPI is reconstructed into and interpreted in a position where it is not licensed. The same effect is predicted to appear in the extended sentence at \#2, i. e. verbieten, except that longer reading times are expected in the +NPI, -LICENSOR.NEG-condition. Here again, the NPI is reconstructed into a position in which it is not licensed. According to previous findings, I expect that reading times at \#2 may be influenced by the presence of an illusory licensor, i. e. a potentially licensing element which precedes the NPI, but is not in a structurally licit position to license the NPI. Additionally, prolonged reading times are also expected in conditions with two negations due to the increased complexity in interpretation. However, double negation should affect the +NPI and the -NPI condition equally. 


\subsubsection{Participants}

We tested 41 participants (age 18-34 years, mean 23 year; 11 male), all students of the University of Konstanz, self-declared native speakers of German, and righthanded. Participants received a reimbursement of $5 €$ for participation.

\subsubsection{Procedure}

The experiment was carried out in a centered self-paced reading paradigm (Just et al. 1982) in which the segments were presented non-cumulatively in a stationary window. This mode of presentation provided no visual cues that would allow the participants to predict the length of the sentences. For each item, the participants saw the context sentences and the target sentence presented in a word-per-word fashion in the middle of the screen. Participant moved through the segments at their own pace by pressing the space bar. In approximately half of the stimuli a yes-no comprehension question was displayed after the final segment. Participants had to choose the correct answer by pressing the ' $f$ ' or ' $j$ ' key on a German keyboard. After each response the participants saw a feedback message whether their response was correct or not. Participants were instructed to read the sentences and to answer the questions as fast as possible in order to give correct responses.

The procedure was set up with the experiment software package Linger $^{3}$ and run on a Windows PC in a psycholinguistics lab. The experimental stimuli were randomized according to the Latin square design, such that each participant saw each of the 32 items in exactly one of the 8 experimental conditions. The total list of stimuli (experimental items plus fillers) were automatically randomized by the experiment software. Experiments took approximately 20 minutes.

\subsubsection{Data analysis}

Prior to the analysis, all data points with reading times larger than 2 seconds $(n=48)$ have been excluded $(0.2 \%$ of the data). The data analysis was carried out by use of the statistical software package $R$ (R Core Team 2015). I used linear mixed-effects models of the lme4 package (Bates et al. 2013) to analyze the logtransformed reading times. ${ }^{4}$ Following arguments in Barr et al. (2013) and Bates et al. (2015), I fitted maximal justified random-effect structures for the LME-models. I performed a model criticism as recommended in Baayen \& Milin (2010) by exclud-

\footnotetext{
3 Written by Doug Rhode available at http://tedlab.mit.edu/ dr/Linger/

4 Reading times were log-transformed to achieve a distribution of the data points that resemble a normal distribution.
} 
ing absolute standardized residuals exceeding 2.5 standard deviations. I report the results of the criticized model, taking effects as significant if the respective $\mathrm{t}$-value exceeds an absolute value of 2 . I will report the fixed-effect coefficients of all analysis that showed significant effects below by indicating the exact model specifications.

The analysis of the reading times proceeded in two steps: The initial sequence of the target sentences including the adverbial unter Umständen was identical for the \pm LICENSOR.NEG conditions. These two conditions are aggregated for the analysis of this region, resulting in a $2 \times 2$ analysis. Only for the remaining segments, a full $2 \times 2 \times 2$ analysis including all 8 experimental condition were applied.

The participants' accuracy in response to the comprehension questions ranged from $71-100 \%$ (mean $87 \%$ ). No participant was excluded from the analysis.

\subsubsection{Results}

First infinitive + adverb: The reading time results for the first region of interest are presented in Figure 6.1. No effects could be detected at the negation and the infinitive particle $z u$ 'to'. At the following three segments, the infinitive drucken 'print', the first adverb segment unter 'under', and the second adverb segment Umständen 'circumstances', the $2 \times 2$ analysis revealed an interaction of both factors MATRIX.VERB and +ILLUSORY.NEG $(t=-3.2511, t=-2.0309$, and $t=-1.6003$ respectively) indicating that the +NPI -ILLUSORY.NEG condition shows longer reading times than all other conditions. Whereas the significance increases after model criticism for the first two segments, the t-value of the interaction term of the second adverb segment drops below significance. However, the direct comparison between the -NPI -ILLUSORY.NEG and the +NPI -ILLUSORY.NEG remains significant for all three segments $(t=2.8084, t=3.2666$, and $t=2.5077$ respectively). Additionally, an analysis of the summed reading times for this 3-segment region also revealed a significant direct comparison $(t=3.6767)$ and a significant interaction $(t=-3.0239)$. The exact model outputs of these analyses are given in Tables 6.1 to 6.4 .

The reading times for the second region, i. e. the segments following the LICENSING.NEG are displayed in Figure 6.2. The results can be divided into two subregions, the second infinitive and the spillover region.

Second infinitive: No effects could be detected on the second negation. On the particle of the second infinitive $z u$, which followed directly after the LicENsING.NEG, the analysis revealed contrasts for both negations, the LICENSING.NEG $(t=-2.3089)$ and the ILLUSORY.NEG $(t=-2.6988)$, signaling that presence of the 




Figure 6.1: Mean reading times for the first infinitive + adverb region of Experiment $2(95 \% \mathrm{Cl})$

negations yields longer reading times. Additionally, the model revealed an interaction of the MATRIX.VERB and the ILLUSORY.NEG $(t=2.0343)$ which indicates that, for the -NPI matrix verb, both negations increase reading times whereas for the +NPI, only the directly preceding LICENSING.NEG affects reading times and the earlier ILLUSORY.NEG has no significant impact on the reading times. On the infinitive verbieten 'forbid' the model yielded only a contrast of LICENSING.NEG $(t=-2.3346)$ with longer reading times for a present negation. The analysis of the aggregated reading times of the particle and the infinitive $z u$ verbieten 'to forbid' revealed a significant contrast of LICENSING.NEG $(t=-2.9335)$ and a strong tendency of ILLUSORY.NEG $(t=-1.9718)$ for the - NPI verb. The exact model outputs for this subregion are given in Tables 6.5 to 6.7 .

Spillover region: No effect could be detected on the first two segments of the spillover region, the complementizer um 'for' and the determiner das 'the'. On the adjective of the spillover region mediale 'medial', the analysis revealed an effect of MATRIX.VERB ( $t=-2.6226)$, LICENSING.NEG $(t=-2.0702)$, and ILLUSORY.NEG $(t=-2.5632)$ as well as an interaction of MATRIX.VERB and ILLUSORY.NEG $(t=2.1532)$. Essentially, this indicates that the ungrammatical condition in which the +NPI verb is preceded only by the ILLUSORY.NEG, yields longer reading times than all other conditions. On the noun Interesse 'interest' the model revealed an effect of LICENSING.NEG $(t=2.1943)$ for the - NPI verbs with longer reading times for the negation present. On the following infinitive particle $z u$ 'to', the model revealed a 3-way interaction of MATRIX.VERB, LICENSING.NEG, and ILLUSORY.NEG $(t=2.1173)$, indicating a significant contrast between the non-negated -NPI condition with shortest reading times and the doubly-negated +NPI condition with longest reading times. On the final segment, i.e. the infinitive wecken 
'arouse', the model revealed several significant contrasts which indicate that the non-negated -NPI condition shows shorter reading times than all other condition, as clearly visible in Figure 6.2. The analysis of the aggregated reading times of the three final segments Interesse zu wecken 'interest to arouse' yielded the same combination of contrasts, which have been found on the final segment, namely that the non-negated -NPI showed shorter reading times than all other conditions. The exact model outputs for this region are given in Tables 6.8 to 6.12 .



Figure 6.2: Mean reading times for the high VP + spillover region of Experiment $2(95 \% \mathrm{Cl})$

\subsubsection{Discussion}

In line with the predictions of the V2-Reconstruction Hypothesis, the results show increased reading times for non-licensed NPI from the first infinitive drucken onwards. As illustrated for the materials in (6) and (7), this is the segment which directly precedes the first reconstruction site. This indicates that, after integrating drucken into the parse, the finite verb will be automatically reconstructed and interpreted. If the finite verb is the NPI brauchen, it must be properly licensed at this point. In the +NPI -ILLUSORY.NEG condition, no such licensor is present. This temporary licensing failure results in prolonged reading times which extend to the two following segments, showing the same effect profile with respect to polar- 
ity and temporal extension as in previous studies of non-licensed NPIs in surface position (e.g. Parker \& Phillips 2016).

At the second infinitive region $z u$ verbieten, the result did not indicate an immediate effect of NPI-licensing in contrast to the predictions above. For both verb types, the presence of an immediately preceding LICENSING.NEG led to longer reading times. However, at the particle of the second infinitive $z u$, a statistical interaction turned up which indicates that NPI-licensing does affect reading times at this point: For the -NPI verb beschließen reading times are shortest in the condition without negation, and the presence of each negation increases reading times in an additive fashion. For the +NPI verbs only the directly preceding negation, the LICENSING.NEG, increased reading times. The non-negated condition, being ungrammatical, shows comparably longer reading times, i. e. as long as all singly negated conditions.

In the spillover region, the analysis revealed a correlate of NPI-licensing failure. At the adjective mediale, the model detected significantly longer reading times for the +NPI verb that was preceded only by the illusory negation (+NPI, +ILLUSORY.NEG, -LICENSOR.NEG). In contrast to the predictions, this effect was very local and affected only one of two ungrammatical conditions. I assume that this effect reflects a delayed evaluation of the licensing conditions. Further, I assume that the delay is due to the complexity of the sentence with two embedded infinitives, which impedes the evaluation of the NPI-licensing. I suspect that the -ILLUSORY.NEG -LICENSOR.NEG condition, in which no possible NPI-licensor is present, is so demanding that the processor gives up and switches to a more shallow parsing mode which explains why no prolonged reading times corresponding to the ungrammaticality are observable at the spillover region. Interestingly, at the three clause-final segments, the results show a distance effect of negation. The non-negated -NPI verb condition showed the shortest reading times of all conditions, which indicate that simple and double negation does impact processing at the clause-final region. The non-negated +NPI condition, however, patterns with negated condition, due to its non-licensed NPI.

One weak point of the material is, that in the first region, where we found the predicted interaction, the distance between the position of the negation and the reconstruction site of the NPI is very small. An alternative explanation can therefore be that the prolonged reading times in the +NPI, -ILLUSORY.NEG condition is a consequence of the missing negation without resorting to a reconstruction analysis. ${ }^{5}$ If the NPI is interpreted in the C-domain, a negation is expected. If this expectation is not satisfied, the reading times increase on the elements following

5 Thanks to Barbara Tomaszewicz for pointing this out. 
the canonical position of the negation. In the next section, I report the results of a follow-up experiment which refutes the predictions of this alternative explanation. Additionally, I would expect that such an expectation-based effect would emerge in the same way at the second VP region (nicht zu verbieten), contrary to the results. The fact that the effect in the second region is delayed and sensitive to the illusory negation renders it more plausible that the effect is tied to an interpretative mechanism of NPI-licensing rather than a simple expectation of a negation. Moreover, an expectation-based approach is not able to explain the special status of the illusory licensing, which, however, has been reported in other experiments employing different experimental methods.

In sum, the results of the experiment closely match the predictions of the V2Reconstruction Hypothesis in the first region. In the second region, the results are compatible with the V2-Reconstruction Hypothesis but the high complexity of the embedded clause structure seems to have attenuated the effect considerably.

Table 6.1: Output of the LME model for first inifinitive (drucken) in Experiment 2 lmer (log.RT Matrix.Verb*Illusory.Neg+trial+segment. length+ $(1+$ Matrix.Verb*Illusory. Neg|participant. ID)+ (1+Matrix.Verb*Illusory. Neg|stimulus. ID))

\begin{tabular}{lrrrrrr}
\hline & \multicolumn{3}{c}{ criticized model } & \multicolumn{3}{c}{ raw model } \\
\cline { 2 - 7 } & Estimate & \multicolumn{1}{c}{ SE } & $\mathrm{t}$ & Estimate & SE & $\mathrm{t}$ \\
\hline Intercept (-NPI -ILLUSORY.NEG) & 5.7665 & 0.0431 & 133.8110 & 5.7966 & 0.0457 & 126.8162 \\
MATRIX.VERB (+NPI) & 0.0633 & 0.0225 & 2.8084 & 0.0733 & 0.0256 & 2.8607 \\
+lLLUSORY.NEG (NEG) & 0.0281 & 0.0157 & 1.7885 & 0.0141 & 0.0206 & 0.6820 \\
trial & -0.0038 & 0.0003 & -14.6113 & -0.0042 & 0.0003 & -12.3711 \\
Segment length & 0.0130 & 0.0026 & 4.9311 & 0.0123 & 0.0033 & 3.7079 \\
MatRIX.VERB:ILLUSORY.NEG & -0.0808 & 0.0249 & -3.2511 & -0.0707 & 0.0307 & -2.3062 \\
\hline
\end{tabular}


Table 6.2: Output of the LME model for first adverb segment (unter) in Experiment 2 lmer (log. RT Matrix. Verb*Illusory. Neg+trial+segment. length+ (1+Matrix.Verb*Illusory. Neg|participant. ID)+ (1+Matrix.Verb*Illusory. Neg|stimulus. ID))

\begin{tabular}{lrrrrrrr}
\hline & \multicolumn{3}{c}{ criticized model } & \multicolumn{3}{c}{ raw model } \\
\cline { 2 - 7 } & Estimate & \multicolumn{1}{c}{ SE } & $\mathrm{t}$ & & Estimate & SE & $\mathrm{t}$ \\
\hline Intercept (-NPI -ILLUSORY.NeG) & 5.9148 & 0.0338 & 175.1867 & 5.9347 & 0.0364 & 163.2562 \\
MATRIX.VERB (+NPI) & 0.0638 & 0.0195 & 3.2666 & 0.0478 & 0.0234 & 2.0414 \\
+lLLUSORY.NEG (NEG) & 0.0034 & 0.0165 & 0.2084 & 0.0067 & 0.0221 & 0.3051 \\
trial & -0.0038 & 0.0003 & -14.1245 & -0.0034 & 0.0003 & -9.9244 \\
Segment length & -0.0017 & 0.0033 & -0.4993 & -0.0018 & 0.0045 & -0.4040 \\
MATRIX.VERB:ILlUSORY.NeG & -0.0514 & 0.0253 & -2.0309 & -0.0435 & 0.0306 & -1.4224 \\
\hline
\end{tabular}

Table 6.3: Output of the LME model for second adverb segment (Umständen) in Experiment 2 lmer (log. RT Matrix. Verb*Illusory. Neg+trial+segment. length+ (1+Matrix.Verb+Illusory. Neg|participant. ID)+ (1+Matrix.Verb+Illusory. Neg|stimulus. ID))

\begin{tabular}{lrrrrrr}
\hline & \multicolumn{3}{c}{ criticized model } & \multicolumn{3}{c}{ raw model } \\
\cline { 2 - 7 } & Estimate & \multicolumn{1}{c}{ SE } & $\mathrm{t}$ & Estimate & SE & $\mathrm{t}$ \\
\hline Intercept (-NPI -ILLUSORY.NeG) & 5.8850 & 0.0408 & 144.1579 & 5.8854 & 0.0433 & 135.9400 \\
MATRIX.VERB (+NPI) & 0.0393 & 0.0157 & 2.5077 & 0.0617 & 0.0195 & 3.1591 \\
+ILLUSORY.NEG (NEG) & -0.0055 & 0.0161 & -0.3440 & 0.0084 & 0.0188 & 0.4455 \\
trial & -0.0035 & 0.0003 & -13.1883 & -0.0033 & 0.0003 & -10.3265 \\
Segment length & 0.0019 & 0.0028 & 0.7003 & 0.0027 & 0.0031 & 0.8776 \\
MATRIX.VeRB:ILLUSORY.NeG & -0.0323 & 0.0202 & -1.6003 & -0.0583 & 0.0250 & -2.3351 \\
\hline
\end{tabular}

Table 6.4: Output of the LME model for first inifinitive + adverb region (drucken unter Umständen) in Experiment 2

lmer (log.RT Matrix. Verb*Illusory. Neg+trial+segment. length+ (1+Matrix.Verb*Illusory. Neg|participant. ID)+ (1+Matrix.Verb*Illusory. Neg|stimulus. ID))

\begin{tabular}{lrrrrrr}
\hline & \multicolumn{3}{c}{ criticized model } & \multicolumn{3}{c}{ raw model } \\
\cline { 2 - 7 } & Estimate & \multicolumn{1}{c}{ SE } & $\mathrm{t}$ & Estimate & SE & $\mathrm{t}$ \\
\hline Intercept (-NPI -ILLUSORY.NEG) & 6.9783 & 0.0429 & 162.8133 & 7.0083 & 0.0469 & 149.4134 \\
MATRIX.VERB (+NPI) & 0.0673 & 0.0183 & 3.6767 & 0.0651 & 0.0196 & 3.3113 \\
+lLLUSORY.NeG (NEG) & 0.0120 & 0.0128 & 0.9367 & 0.0126 & 0.0154 & 0.8199 \\
trial & -0.0040 & 0.0002 & -19.0776 & -0.0037 & 0.0003 & -14.3091 \\
Segment length & 0.0015 & 0.0014 & 1.0568 & 0.0007 & 0.0017 & 0.4087 \\
MATRIX.Verb:ILlUSORY.NEG & -0.0639 & 0.0211 & -3.0239 & -0.0616 & 0.0244 & -2.5251 \\
\hline
\end{tabular}


Table 6.5: Output of the LME model for second infinitive particle $(z u)$ in Experiment 2 Imer ( $\log$. RT Matrix. Verb*Licensor. Neg*Illusory. Neg+trial+ (1+Matrix.Verb*Licensor. Neg+Illusory. Neg|participant. ID)+ (1+Matrix.Verb*Licensor. Neg+Illusory.Neg|stimulus. ID))

\begin{tabular}{lrrrrrr}
\hline & \multicolumn{3}{c}{ criticized model } & \multicolumn{3}{c}{ raw model } \\
\cline { 2 - 8 } & Estimate & \multicolumn{1}{c}{ SE } & \multicolumn{1}{c}{$\mathrm{t}$} & Estimate & \multicolumn{1}{c}{ SE } & \multicolumn{1}{c}{$\mathrm{t}$} \\
\hline Intercept (-NPI +LIC.NEG+ILL.NEG) & 5.9589 & 0.0384 & 155.2760 & 5.9777 & 0.0405 & 147.6867 \\
MATRIX.VERB (+NPI) & -0.0202 & 0.0213 & -0.9485 & -0.0027 & 0.0274 & -0.0997 \\
-LICENSOR.NEG (POS) & -0.0506 & 0.0219 & -2.3089 & -0.0528 & 0.0282 & -1.8746 \\
-ILLUSORY.NEG (POS) & -0.0561 & 0.0208 & -2.6988 & -0.0480 & 0.0265 & -1.8151 \\
trial & -0.0040 & 0.0003 & -15.8086 & -0.0036 & 0.0003 & -10.9976 \\
MATRIX.VERB:LICENSOR.NEG & -0.0096 & 0.0292 & -0.3286 & -0.0275 & 0.0380 & -0.7224 \\
MATRIX.VERB:ILLUSORY.NEG & 0.0561 & 0.0276 & 2.0343 & 0.0263 & 0.0352 & 0.7465 \\
LICENSOR.NEG:ILLUSORY.NEG & 0.0155 & 0.0275 & 0.5628 & -0.0004 & 0.0352 & -0.0126 \\
M.VERB:LIC.NEG:ILL.NEG & 0.0017 & 0.0388 & 0.0443 & 0.0398 & 0.0497 & 0.7997 \\
\hline
\end{tabular}

Table 6.6: Output of the LME model for second infinitive (verbieten) in Experiment 2 lmer (log. RT Matrix. Verb*Licensor. Neg*Illusory. Neg+trial+segment. length+ (1+Matrix.Verb*Licensor. Neg+Illusory. Neg|participant. ID)+ (1+Matrix.Verb+Licensor.Neg+Illusory.Neg|stimulus. ID))

\begin{tabular}{lrrrrrr}
\hline & \multicolumn{3}{c}{ criticized model } & \multicolumn{3}{c}{ raw model } \\
\cline { 2 - 8 } & \multicolumn{1}{c}{ Estimate } & \multicolumn{1}{c}{$\mathrm{SE}$} & \multicolumn{1}{c}{$\mathrm{t}$} & Estimate & \multicolumn{1}{c}{$\mathrm{SE}$} & \multicolumn{1}{c}{$\mathrm{t}$} \\
\hline Intercept (-NPI +LIC.NeG+ILL.NEG) & 5.8755 & 0.0860 & 68.2893 & 5.8683 & 0.0896 & 65.4978 \\
MATRIX.VERB (+NPI) & -0.0182 & 0.0378 & -0.4821 & -0.0493 & 0.0413 & -1.1935 \\
-LICENSOR.NEG (POS) & -0.0836 & 0.0358 & -2.3346 & -0.0971 & 0.0430 & -2.2560 \\
-ILLUSORY.NEG (POS) & -0.0458 & 0.0365 & -1.2544 & -0.0463 & 0.0419 & -1.1063 \\
trial & -0.0052 & 0.0004 & -12.6238 & -0.0051 & 0.0005 & -10.4942 \\
Segment.length & 0.0251 & 0.0055 & 4.5857 & 0.0302 & 0.0058 & 5.2455 \\
MATRIX.VERB:LICENSOR.NEG & 0.0428 & 0.0507 & 0.8445 & 0.0585 & 0.0552 & 1.0592 \\
MATRIX.VERB:ILLUSORY.NEG & 0.0459 & 0.0441 & 1.0403 & 0.0483 & 0.0526 & 0.9191 \\
LICENSOR.NeG:ILLUSORY.NeG & 0.0509 & 0.0442 & 1.1505 & 0.0606 & 0.0526 & 1.1516 \\
M.VERB:LIC.NEG:ILL.NEG & -0.0344 & 0.0622 & -0.5530 & -0.0400 & 0.0743 & -0.5380 \\
\hline
\end{tabular}


Table 6.7: Output of the LME model for second infinitive region (zu verbieten) in Experiment 2 lmer (log. RT Matrix. Verb*Licensor. Neg*Illusory. Neg+trial+segment. length+ (1+Matrix. Verb*Licensor. Neg+Illusory. Neg|participant. ID)+ (1+Matrix.Verb*Licensor. Neg+Illusory.Neg|stimulus. ID))

\begin{tabular}{lrrrrrr}
\hline & \multicolumn{3}{c}{ criticized model } & \multicolumn{3}{c}{ raw model } \\
\cline { 2 - 7 } & Estimate & \multicolumn{1}{c}{ SE } & \multicolumn{1}{c}{$\mathrm{t}$} & Estimate & \multicolumn{1}{c}{ SE } & $\mathrm{t}$ \\
\hline Intercept (-NPI +LIC.NEG+ILL.NEG) & 6.5631 & 0.0695 & 94.4143 & 6.5559 & 0.0771 & 84.9951 \\
MATRIX.VERB (+NPI) & -0.0226 & 0.0266 & -0.8497 & -0.0343 & 0.0314 & -1.0936 \\
-LICENSOR.NEG (POS) & -0.0763 & 0.0260 & -2.9335 & -0.0903 & 0.0328 & -2.7512 \\
-ILLUSORY.NEG (POS) & -0.0533 & 0.0270 & -1.9718 & -0.0548 & 0.0317 & -1.7278 \\
trial & -0.0046 & 0.0003 & -15.0917 & -0.0045 & 0.0004 & -12.2199 \\
Segment.length & 0.0167 & 0.0036 & 4.5958 & 0.0198 & 0.0044 & 4.4622 \\
MATRIX.VERB:LICENSOR.NEG & 0.0259 & 0.0360 & 0.7176 & 0.0321 & 0.0422 & 0.7610 \\
MATRIX.VERB:ILLUSORY.NEG & 0.0403 & 0.0329 & 1.2250 & 0.0392 & 0.0399 & 0.9845 \\
LICENSOR.NEG:ILLUSORY.NEG & 0.0540 & 0.0329 & 1.6443 & 0.0466 & 0.0399 & 1.1679 \\
M.VERB:LIC.NEG:ILL.NEG & -0.0282 & 0.0463 & -0.6096 & -0.0125 & 0.0563 & -0.2219 \\
\hline
\end{tabular}

Table 6.8: Output of the LME model for the adjective of the spillover region (mediale) in Experiment 2

Imer (log.RT Matrix.Verb*Licensor. Neg*Illusory. Neg+trial+segment. length+ (1+Matrix. Verb*Licensor. Neg+Illusory. Neg|participant. ID)+ (1+Matrix.Verb+Licensor. Neg+Illusory.Neg|stimulus. ID))

\begin{tabular}{lrrrrrr}
\hline & \multicolumn{3}{c}{ criticized model } & \multicolumn{3}{c}{ raw model } \\
\cline { 2 - 7 } & Estimate & \multicolumn{1}{c}{ SE } & \multicolumn{1}{c}{$\mathrm{t}$} & Estimate & \multicolumn{1}{c}{ SE } & $\mathrm{t}$ \\
\hline Intercept (+NPI -LIC.NEG+ILL.NEG) & 5.8620 & 0.0456 & 128.4976 & 5.9030 & 0.0489 & 120.7331 \\
MATRIX.VERB (-NPI) & -0.0623 & 0.0237 & -2.6226 & -0.0429 & 0.0286 & -1.4970 \\
+LICENSOR.NEG (NEG) & -0.0467 & 0.0226 & -2.0702 & -0.0412 & 0.0270 & -1.5292 \\
-ILLUSORY.NEG (POS) & -0.0560 & 0.0218 & -2.5632 & -0.0508 & 0.0269 & -1.8903 \\
trial & -0.0042 & 0.0003 & -15.0489 & -0.0040 & 0.0003 & -11.9231 \\
Segment.length & 0.0092 & 0.0022 & 4.1973 & 0.0065 & 0.0027 & 2.4600 \\
MATRIX.VERB:LICENSOR.NEG & 0.0439 & 0.0304 & 1.4440 & 0.0141 & 0.0375 & 0.3762 \\
MATRIX.VERB:ILLUSORY.NEG & 0.0651 & 0.0302 & 2.1532 & 0.0444 & 0.0368 & 1.2045 \\
LICENSOR.NEG:ILLUSORY.NEG & 0.0488 & 0.0301 & 1.6213 & 0.0326 & 0.0368 & 0.8856 \\
M.VERB:LIC.NEG:ILL.NEG & -0.0655 & 0.0427 & -1.5342 & -0.0257 & 0.0521 & -0.4926 \\
\hline
\end{tabular}


Table 6.9: Output of the LME model for the noun of the spillover region (Interesse) in Experiment 2

Imer (log. RT Matrix. Verb*Licensor . Neg*Illusory. Neg+trial+segment. length+ (1+Matrix.Verb*Licensor. Neg+Illusory. Neg|participant.ID)+ (1+Matrix.Verb*Licensor. Neg+Illusory.Neg|stimulus. ID))

\begin{tabular}{|c|c|c|c|c|c|c|}
\hline & \multicolumn{3}{|c|}{ criticized model } & \multicolumn{3}{|c|}{ raw model } \\
\hline & Estimate & SE & $\mathrm{t}$ & Estimate & SE & $\mathrm{t}$ \\
\hline Intercept (-NPI -LIC.NEG-ILL.NEG) & 5.7349 & 0.0422 & 135.8538 & 5.7375 & 0.0433 & 132.5118 \\
\hline MATRIX.VERB (+NPI) & 0.0394 & 0.0233 & 1.6882 & 0.0535 & 0.0272 & 1.9655 \\
\hline +LICENSOR.NEG (NEG) & 0.0556 & 0.0253 & 2.1943 & 0.0725 & 0.0289 & 2.5117 \\
\hline +ILLUSORY.NEG (NEG) & 0.0006 & 0.0213 & 0.0262 & 0.0159 & 0.0272 & 0.5840 \\
\hline trial & -0.0034 & 0.0003 & -12.6887 & -0.0036 & 0.0003 & -10.8754 \\
\hline segment.length & 0.0152 & 0.0020 & 7.6812 & 0.0156 & 0.0021 & 7.3593 \\
\hline MATRIX.VERB:LICENSOR.NEG & -0.0523 & 0.0315 & -1.6618 & -0.0732 & 0.0376 & -1.9441 \\
\hline MATRIX.VERB:ILLUSORY.NEG & -0.0087 & 0.0288 & -0.3010 & -0.0177 & 0.0360 & -0.4919 \\
\hline LICENSOR.NEG:ILLUSORY.NEG & -0.0205 & 0.0288 & -0.7136 & -0.0547 & 0.0361 & -1.5168 \\
\hline M.VERB:LIC.NEG:ILL.NEG & 0.0338 & 0.0407 & 0.8309 & 0.0577 & 0.0510 & 1.1316 \\
\hline
\end{tabular}

Table 6.10: Output of the LME model for the infinitive particle of the spillover region $(z u)$ in Experiment 2

lmer (log.RT Matrix.Verb*Licensor. Neg*Illusory. Neg+trial+ (1+Matrix.Verb+Licensor. Neg+Illusory. Neg|participant.ID)+ (1+Matrix.Verb+Licensor. Neg+Illusory. Neg|stimulus. ID))

\begin{tabular}{|c|c|c|c|c|c|c|}
\hline & \multicolumn{3}{|c|}{ criticized model } & \multicolumn{3}{|c|}{ raw model } \\
\hline & Estimate & SE & $\mathrm{t}$ & Estimate & SE & $\mathrm{t}$ \\
\hline Intercept (-NPI -LIC.NEG-ILL.NEG) & 5.8796 & 0.0295 & 199.6061 & 5.8879 & 0.0287 & 204.9369 \\
\hline MATRIX.VERB (+NPI) & 0.0130 & 0.0179 & 0.7277 & 0.0121 & 0.0224 & 0.5394 \\
\hline +LICENSOR.NEG (NEG) & 0.0184 & 0.0185 & 0.9911 & 0.0230 & 0.0231 & 0.9991 \\
\hline +ILLUSORY.NEG (NEG) & 0.0061 & 0.0189 & 0.3247 & 0.0153 & 0.0229 & 0.6663 \\
\hline trial & -0.0027 & 0.0002 & -11.5572 & -0.0028 & 0.0003 & -9.8815 \\
\hline MATRIX.VERB:LICENSOR.NEG & -0.0311 & 0.0252 & -1.2329 & -0.0273 & 0.0313 & -0.8714 \\
\hline MATRIX.VERB:ILLUSORY.NEG & -0.0057 & 0.0253 & -0.2248 & -0.0010 & 0.0314 & -0.0306 \\
\hline LICENSOR.NEG:ILLUSORY.NEG & -0.0413 & 0.0254 & -1.6286 & -0.0165 & 0.0313 & -0.5258 \\
\hline M.VERB:LIC.NEG:ILL.NEG & 0.0758 & 0.0358 & 2.1173 & 0.0393 & 0.0443 & 0.8875 \\
\hline
\end{tabular}


Table 6.11: Output of the LME model for the verb of the spillover region (wecken) in Experiment 2

Imer (log. RT Matrix. Verb*Licensor. Neg*Illusory. Neg+trial+segment. length+ (1+Matrix.Verb+Licensor. Neg+Illusory. Neg/participant. ID)+

$(1+$ Licensor. Neg|stimulus. ID))

\begin{tabular}{|c|c|c|c|c|c|c|}
\hline & \multicolumn{3}{|c|}{ criticized model } & \multicolumn{3}{|c|}{ raw model } \\
\hline & Estimate & SE & $\mathrm{t}$ & Estimate & SE & $\mathrm{t}$ \\
\hline Intercept (-NPI -LIC.NEG-ILL.NEG) & 5.8449 & 0.0561 & 104.1871 & 5.8542 & 0.0615 & 95.1699 \\
\hline MATRIX.VERB (+NPI) & 0.0712 & 0.0274 & 2.6016 & 0.0750 & 0.0328 & 2.2854 \\
\hline +LICENSOR.NEG (NEG) & 0.0772 & 0.0258 & 2.9915 & 0.1006 & 0.0335 & 3.0020 \\
\hline +ILLUSORY.NEG (NEG) & 0.0896 & 0.0257 & 3.4810 & 0.0896 & 0.0332 & 2.7001 \\
\hline trial & -0.0040 & 0.0003 & -11.9502 & -0.0039 & 0.0004 & -9.2995 \\
\hline segment.length & 0.0078 & 0.0035 & 2.2231 & 0.0087 & 0.0044 & 1.9860 \\
\hline MATRIX.VERB:LICENSOR.NEG & -0.0661 & 0.0356 & -1.8548 & -0.0962 & 0.0456 & -2.1091 \\
\hline MATRIX.VERB:ILLUSORY.NEG & -0.1085 & 0.0357 & -3.0411 & -0.1024 & 0.0457 & -2.2423 \\
\hline LICENSOR.NEG:ILLUSORY.NEG & -0.0920 & 0.0358 & -2.5667 & -0.0804 & 0.0456 & -1.7617 \\
\hline M.VERB:LIC.NEG:ILL.NEG & 0.1120 & 0.0506 & 2.2140 & 0.1065 & 0.0645 & 1.6501 \\
\hline
\end{tabular}

Table 6.12: Output of the LME model for the final 3-segments-region of the spillover region (Interesse zu wecken) in Experiment 2

lmer (log. RT Matrix. Verb*Licensor. Neg*Illusory. Neg+trial+segment. length+ (1+Matrix. Verb*Licensor. Neg+Illusory. Neg|participant. ID)+ (0+Matrix.Verb*Licensor. Neg+Illusory. Neg|stimulus. ID))

\begin{tabular}{lrrrrrr}
\hline & \multicolumn{3}{c}{ criticized model } & \multicolumn{3}{c}{ raw model } \\
\cline { 2 - 7 } & Estimate & \multicolumn{1}{c}{ SE } & \multicolumn{1}{c}{$\mathrm{t}$} & Estimate & \multicolumn{1}{c}{ SE } & $\mathrm{t}$ \\
\hline Intercept (-NPI -LIC.NEG-ILL.NEG) & 6.8719 & 0.0463 & 148.3777 & 6.8899 & 0.0483 & 142.7712 \\
MATRIX.VERB (+NPI) & 0.0455 & 0.0177 & 2.5709 & 0.0487 & 0.0213 & 2.2874 \\
+LICENSOR.NEG (NEG) & 0.0616 & 0.0175 & 3.5227 & 0.0716 & 0.0221 & 3.2397 \\
+ILLUSORY.NEG (NEG) & 0.0466 & 0.0169 & 2.7602 & 0.0467 & 0.0218 & 2.1404 \\
trial & -0.0037 & 0.0002 & -16.8791 & -0.0035 & 0.0003 & -12.7953 \\
Segment.length & 0.0063 & 0.0014 & 4.5722 & 0.0060 & 0.0015 & 3.8688 \\
MATRIX.VERB:LICENSOR.NeG & -0.0470 & 0.0238 & -1.9747 & -0.0659 & 0.0301 & -2.1895 \\
MATRIX.VERB:ILLUSORY.NEG & -0.0562 & 0.0233 & -2.4100 & -0.0478 & 0.0300 & -1.5937 \\
LICENSOR.NEG:ILLUSORY.NEG & -0.0436 & 0.0233 & -1.8702 & -0.0492 & 0.0300 & -1.6411 \\
M.VERB:LIC.NEG:ILL.NEG & 0.0561 & 0.0330 & 1.7001 & 0.0651 & 0.0424 & 1.5369 \\
\hline
\end{tabular}




\subsection{Experiment 3: Follow-up study on the NPI brauchen (self-paced reading)}

This experiment is a follow-up study designed to test the predictions of an alternative explanation of the findings of Experiment 2.

\subsubsection{Rationale}

As noted in Section 6.1.4, the alternative explanation of the increased reading times in Experiment 2 is valid only because the canonical position of the negation and the position at which increased reading times start to emerge (drucken 'print') are separated only by the short infinitive particle $z u$ 'to', as shown in (9a). To contrast the predictions of the two hypotheses, the distance between the canonical position of the negation and the reconstruction position has to be increased. This is achieved by inserting a prepositional phrase between the negation and the infinitive, such as the an den Verlag 'to the publisher' in (9b). ${ }^{6}$

(9) a. Letztendlich braucht der Autor den Roman (nicht) zu drucken \#1 unter finally needs the author the novel not to print under Umständen ... circumstances

b. Letztendlich braucht der Autor den Roman (nicht) [an den Verlag] finally needs the author the novel not at the publisher zu schicken \#1 unter Umständen ... to send under circumstances

In the extended structure (9b), the positions at which the different hypothesis predict longer reading times are now distinguishable. The expectation-based approach predicts that increased reading times due to a non-licensed NPI should appear on the segments following the canonical position of the negation, i.e. on the PP an den Verlag 'at the publisher'. The V2-Reconstruction Hypothesis, on the other hand, predicts that the licensing of the NPI will only be evaluated after reconstruction, i. e. reading times will not increase before the element directly preceding the reconstruction site, i. e. the verb schicken 'send'.

6 Thanks to Daniel Gutzmann for pointing out this possibility of extending the materials. 


\subsubsection{Method}

\subsubsection{Participants}

We tested 48 participants (age 19-37 years, mean 22.9 years; 8 male; 4 left-handed), all self-declared German native speakers ( 5 bilinguals) and students of the University of Cologne. Participants either received course credits or a reimbursement of $4 €$.

\subsubsection{Materials}

The materials consisted of 32 items interspersed with 34 fillers (8 from Experiment 4) resulting in 66 stimuli per participants. All stimuli consisted of an introductory context of 1-2 sentences, a declarative target sentence and a comprehension question (50 \% polar interrogatives and $50 \%$ constituent questions).

An example of an experimental item is given in (10). The target items varied in a $2 \times 3$ design with the factors MATRIX.verb and NEgATION. The finite verb was either the modal NPI-verb brauchen 'need to', as in (10b), (10d), and (10f) or the polarity-neutral verb beschließen 'decide', as in (10c), (10e), and (10g). The materials contained a LOW.NEGATION directly preceding the first infinitive as in (10b-10c), a HIGH.NEGATION preceding the second infinitive, as in (10d-10e), or no negation at all (NO.NEGATION), as in (10f-10g). Generally, the target sentences were very similar to the one from Experiment 2 above. The first major difference is that the materials of this experiment exhibited a PP, such as an den Verlag 'to the publishing company' between the canonical position of the negation and the first infinitive $z$ u schicken 'to send'. As a consequence, the sentences also contained different predicates, namely such that take low argumental or adverbial PPs which canonically follow the sentential negation. Additionally, in comparison to Experiment 2, the number of conditions were reduced by dropping the doubly negated condition in order to eliminate a source of processing difficulty from the materials. Furthermore, I chose to use a different continuation for the conditions with a low negation, in (10b) and (10c). Those structures are not extended by an superordinate VP that would require an additional negation to render the NPI-condition grammatical. Now, only one of the six conditions is ungrammatical, namely (10f) with the NPI brauchen 'need to' and no negation in the sentence. All experimental items are given in the online appendix. 
(10) a. ConteXt:

Ein Autor hat wegen seines neuen Romans Ärger mit seinem Verlag. Er bespricht mit seinem Anwalt, ob er das Manuskript auch an anderer Stelle veröffentlichen kann.

'An author has trouble with his publisher because of his new novel. He talks to his lawyer whether he could publish the manuscript also somewhere else.'

b. +NPI LOW.NEGATION

Letztendlich braucht der Autor den Roman nicht an den Verlag $\mathrm{zu}$ finally NPI the author the novel not at the publisher to schicken \#1 unter Umständen aber an ein Internetportal. send under circumstances however at an internet portal

'Thus the author doesn't have to send the novel to the publisher perhaps however to an internet portal.'

c. -NPI LOW.NEGATION

Letztendlich beschließt der Autor den Roman nicht an den Verlag finally decides the author the novel not at the publisher zu schicken \#1 unter Umständen aber an ein Internetportal. to send under circumstances however at an internet portal

'Thus the author decides to not send the novel to the publisher perhaps however to an internet portal.'

d. +NPI HIGH.NEGATION

Letztendlich braucht der Autor den Roman an den Verlag $\mathrm{zu}$ finally NPI the author the novel at the publisher to schicken \#1 unter Umständen nicht sofort zu verbieten \#2 send under circumstances not immediately to forbid um die rechtlichen Bestimmungen zu wahren. for the legal regulations to preserve

'Thus the author doesn't have to immediately forbid to print the novel this time to preserve the legal regulations.'

e. -NPI HIGH.NEGATION

Letztendlich beschließt der Autor den Roman an den Verlag zu finally decides the author the novel at the publisher to 
schicken \#1 unter Umständen nicht sofort $\quad$ zu verbieten \#2 send under circumstances not immediately to forbid um die rechtlichen Bestimmungen zu wahren. for the legal regulations to preserve 'Thus the author decides to not immediately forbid to print the novel this time to preserve the legal regulations.'

f. +NPI NO.NEGATION

*Letztendlich braucht der Autor den Roman an den Verlag zu finally NPI the author the novel at the publisher to schicken \#1 unter Umständen sofort zu verbieten \#2 um die send under circumstances immediately to forbid for the rechtlichen Bestimmungen zu wahren.

legal regulations to preserve

g. -NPI NO.NEGATION

Letztendlich beschließt der Autor den Roman an den Verlag $\mathrm{zu}$ finally decides the author the novel at the publisher to schicken \#1 unter Umständen sofort zu verbieten \#2 um die send under circumstances immediately to forbid for the rechtlichen Bestimmungen zu wahren.

legal regulations to preserve

'Thus the author decides to immediately forbid to print the novel this time to preserve the legal regulations.'

h. COMPREHENSION QUESTION:

Wer spricht mit seinem Anwalt?

'Who talks to his/its lawyer'

correct answer = Der Autor 'the author' wrong answer = Der Verlag 'the publishing company'

\subsubsection{Procedure}

The context was presented as one text block. The presentation of the target sentence began with a fixation cross and conformed to the centered self-paced reading paradigm (Just et al. 1982) in which the segments were presented noncumulatively in a stationary window, i.e. participants saw only one word at a time at the center of the screen and had no visual cues that would allow them to predict the length of the sentences. Participant moved through the segments at their own pace by pressing the space bar. Each item contained a comprehension question, as in (10h), to control whether participants paid attention to the task. Answers to the comprehension questions were presented in the bottom left and 
right of the screen and were chosen by pressing the 'd' or ' $\mathrm{k}$ ' key on a German keyboard respectively. After each response the participants saw a feedback message indicating whether their response was correct or not. Participants were instructed to read the sentences and to answer the questions as fast as possible in order to give correct responses.

The procedure was programmed in the python experiment suite PsychoPy (Peirce 2007) and run on a Windows PC in a psycholinguistics lab. The experimental stimuli were randomized according to the Latin square design, such that each participant saw each of the 32 items in exactly one of the 6 experimental conditions. The position of the correct answer to the comprehension question (left or right) was balanced across the items. The total list of stimuli (experimental items plus fillers) was automatically randomized by the experiment software. Experiments took approximately 25 minutes.

\subsubsection{Data analysis}

Prior to the analysis, all reading times larger than 2 seconds $(n=43)$ have been excluded ( $0.06 \%$ of the data). The participants' accuracy in response to the comprehension questions ranged from $78-100 \%$ (mean $91 \%$ ). No participant was excluded from the analysis but all trials with a false response to the comprehension question were excluded ( $9.2 \%$ of the data). The statistical handling of the data was identical to the procedure described for Experiment 2.

Data analysis proceeded in two steps: The initial sequence of the target sentences including the adverbial unter Umständen was identical for the HIGH.NEGATION and the NO.NEGATION condition. These two conditions were aggregated for the analysis of this region and contrasted to the LOW.NEGATION condition, resulting in a $2 \times 2$ analysis. The continuations for the LOW.NEGATION conditions differ from the continuation of the remaining four conditions. Hence the analyses for the continuations were carried out separately in a $1 \times 2$ and a $2 \times 2$ fashion respectively.

\subsubsection{Results}

A graphical summary of the result for the initial sequence is given in Figure 6.3. No effects could be detected on the negation and the two following segments of the PP an and den. On the noun of the PP Verlag the analysis revealed a simple effect of MATRIX.VERB $(t=-2.0090)$ with longer reading times for the +NPI condition. On the infinitive particle $z u$, an interaction of MATRIX.VERB and NEGATION turned up indicating that the +NPI LOW.NEGATION condition received shorter reading times than all other conditions. On first infinitive schicken 'send', the statistical anal- 
ysis revealed a significant effect of NEGATION $(t=-2.2931)$ with longer reading times for non-negated sentences. An analysis of the aggregated reading times of the infinitive region ( $z u$ schicken) yielded only a significant effect of NEGATION $(t=-3.1992)$ with longer reading times for non-negated sentences. On the first adverbial segment unter, the analysis revealed a significant contrast in the nonnegated sentences with longer reading times for the non-licensed +NPI condition $(t=-2.5087)$. On the second adverbial segment Umständen the analysis revealed a similar contrast, however, in the negated sentences indicating longer reading times for the $+\mathrm{NPI}$ condition $(t=-2.0064)$. The analysis of the aggregated reading times of the adverb region did not yield significant results. The exact model outputs of the analyses are given in Tables 6.13 to 6.18.

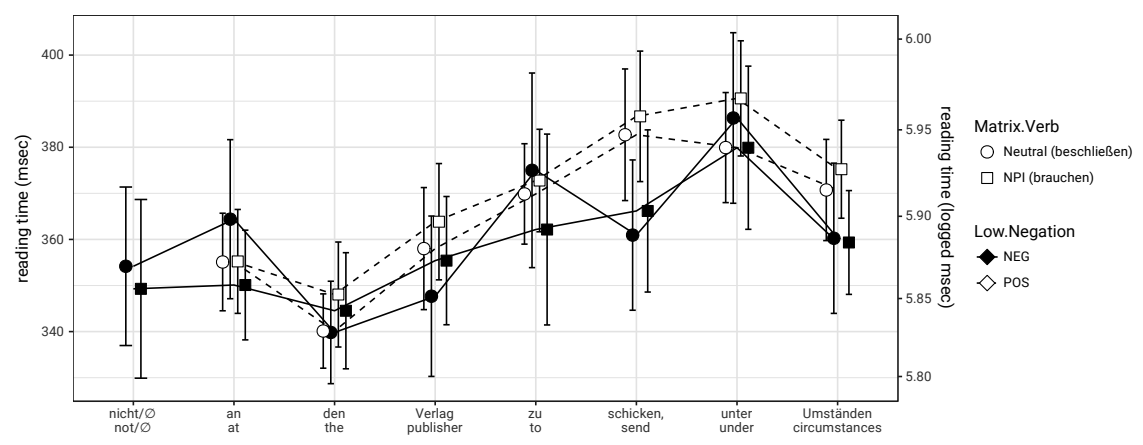

Figure 6.3: Mean reading times for the uniform initial region of interest in Experiment 3 (95\% Cls)

A graphical summary of the spillover region of the LOW.NEGATION conditions is given in Figure 6.4. No effects of the experimental conditions could be detected in this region. Even the contrast on the determiner ein 'an', which appears largest in Figure 6.4, did not reach significance in the raw model and decreased even further after model criticism.

A graphical summary for the continuation of the remaining conditions is presented in Figure 6.5. On the adverbial sofort directly following the negation, the analysis revealed a significant simple effect of NEGATION $(t=-2.3413)$ with longer reading times for the HIGH.NEGATION conditions. On the adjective of the spillover region rechtlichen 'legal', the model revealed a significant contrast for MATRIX.VERB $(t=2.4666)$ and close to significant tendencies for NEgATION $(t=1.9786)$ and the interaction term $(t=-1.9326)$. This indicates that reading times for the -NPI conditions are longer than for the +NPI conditions. Additionally, 


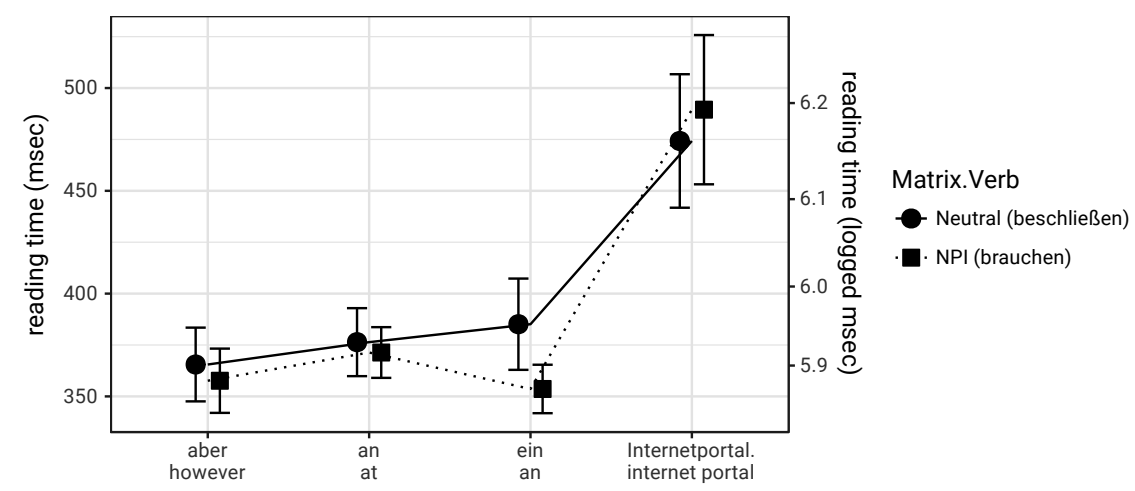

Figure 6.4: Mean reading times for the continuation of the LOW.NEGATION conditions in Experiment 3 (95\% Cls)

negation did not affect the -NPI condition. Within the +NPI condition, however, the ungrammatical NO.NEGATION condition showed longer reading times than the grammatical HIGH.NEGATION condition. No effects could be detected on the other segments. The exact model outputs are given in Tables 6.19 to 6.20.

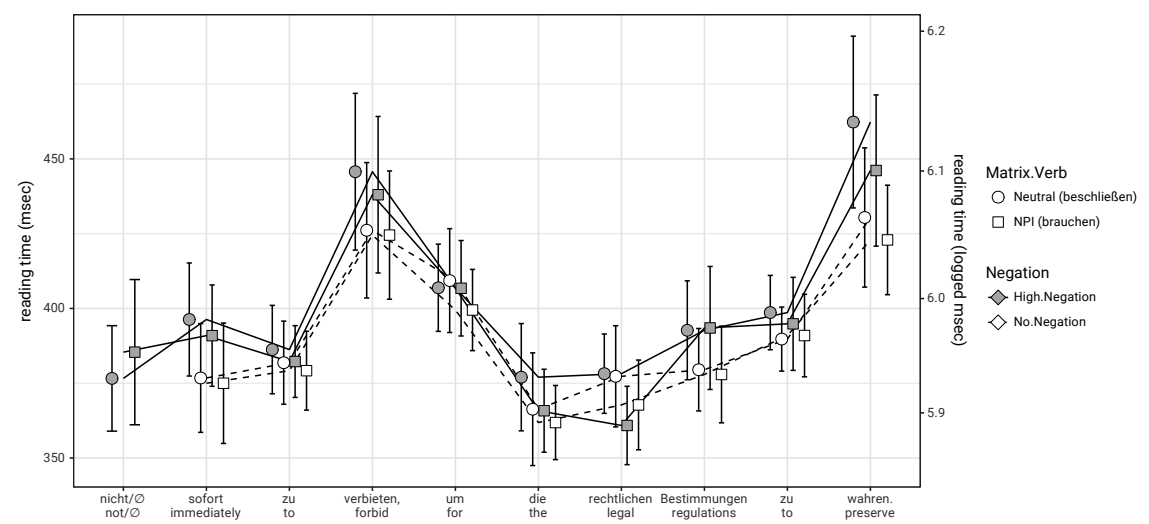

Figure 6.5: Mean reading times for the continuation with the second VP structure in Experiment $3(95 \%$ Cls) 


\subsubsection{Discussion}

The results of this experiment did not replicate the clean interaction pattern of MATRIX.VERB and NEGATION on the first infinitive and the following two segments that was found in Experiment 2. Instead, the results indicated an effect at an earlier position preceding the infinitive, namely at the noun Verlag. Although the temporal profile matches the prediction of the expectation-based account, the form of the effect does not. Remember, this account predicts that an NPI in V2-position triggers an expectation for a negation. If this expectation is violated, we should observe prolonged reading times for the non-licensed +NPI. However, what we observed was longer reading times for NPI-verbs irrespective of negation. This indicates that, at this point, only the content of the V2-position is relevant. The negation seems to impact processing only on the following segments, the infinitive region $z$ u schicken. Again, the result do not indicate that the processor expected a negation only for the NPI-verbs but the results indicate a general effect of negation. However, it is surprising that the presence of negation led to shorter reading times and not to longer ones, as we would plausibly expect. Interestingly, on the two subsequent segments the results showed specific interactions involving longer reading times for the NPI-verbs. This contrast appears on the first adverbial unter only in non-negated sentences and on the second adverbial Umständen only in negated sentences. It seems as if the presence of negation delayed the evaluation of the content of the verb. Although the results are not as predicted, they can receive an explanation under the V2-Reconstruction Hypothesis. The general verb-type effect that shows up at the noun Verlag might be a reflection of an automated reconstruction process. The finite verb is reconstructed and its content is reactivated. This reactivation seems to be more demanding for the +NPI verb brauchen 'need to'. Subsequently, with encounter of the infinitive, the finite verb is reconstructed into a potential base position. At this point, a negation-related process seems to apply. As noted above, it is surprising that this leads to faster processing in the negated sentences. Only on the subsequent segments, the lexical content of the reconstructed verb will be interpreted triggering longer reading times, first in the non-negated sentences and subsequently in the negated sentences.

The remainder of the sentence showed two effects. The first one, on the the adverbial sofort, is most likely a spillover effect from the preceding element. A preceding negation lead to prolonged reading times due to additional semantic processing. The second effect turned up on the adjective of the spillover region rechtliche 'legal'. The interaction at this point indicates that the content of the V2-verbs are interpreted with respect to the second negation. The ungrammatical +NPI NO.NEGATION condition showed longer reading times than the grammat- 
ical +NPI HIGH.NEGATION condition. This indicates that licensing of the NPI is reflected three segments after the second infinitive. Note that a comparable effect was found on the same segment in Experiment 2. This supports the assumption that this is an evaluation of the licensing requirements at the second reconstruction site, that appears a slightly delayed due to the relative complexity of the sentence.

Although the results are not as clear-cut as in Experiment 2, they clearly favor the V2-Reconstruction Hypothesis over the expectation-based approach. Remember that the latter predicted that negation-related effects should appear at the segments directly following the canonical position of the negation, i. e. the PP an den Verlag 'to the publisher'. However, no such effects could be detected at those segments. Distant effects of the negation did not show up until the reconstruction position of the finite verb, i. e. the directly preceding infinitive schicken 'send', as predicted by the V2-Reconstruction Hypothesis.

Table 6.13: Output of the LME model for noun of the PP (Verlag) in Experiment 3 lmer (log. RT Matrix.Verb*Low. Negation+segment. length+trial+ (1+segment. length+trial|participant. ID $)+(1 \mid$ stimulus. ID $))$

\begin{tabular}{lrrrrrr}
\hline & \multicolumn{3}{c}{ criticized model } & \multicolumn{3}{c}{ raw model } \\
\cline { 2 - 7 } & Estimate & \multicolumn{1}{c}{$\mathrm{SE}$} & \multicolumn{1}{c}{$\mathrm{t}$} & Estimate & $\mathrm{SE}$ & \multicolumn{1}{c}{$\mathrm{t}$} \\
\hline Intercept (+NPI -Low.NEGATION) & 5.7416 & 0.0331 & 173.7189 & 5.7324 & 0.0377 & 152.0945 \\
MATRIX.VERB (-NPI) & -0.0253 & 0.0126 & -2.0090 & -0.0246 & 0.0168 & -1.4596 \\
+Low.NEGATION (NEG) & 0.0147 & 0.0153 & 0.9607 & -0.0073 & 0.0206 & -0.3544 \\
segment length & 0.0067 & 0.0029 & 2.3430 & 0.0116 & 0.0033 & 3.4795 \\
trial & -0.0056 & 0.0006 & -9.8937 & -0.0059 & 0.0006 & -9.7096 \\
MATRIX.VERB:LOW.NEGATION & -0.0149 & 0.0219 & -0.6796 & -0.0095 & 0.0293 & -0.3255 \\
\hline
\end{tabular}

Table 6.14: Output of the LME model for particle of the first infinitive $(z u)$ in Experiment 3 lmer (log. RT Matrix.Verb*Low. Negation+segment. length+trial+ (1+trial|participant. ID)+(1|stimulus. ID))

\begin{tabular}{lrrrrrr}
\hline & \multicolumn{3}{c}{ criticized model } & \multicolumn{3}{c}{ raw model } \\
\cline { 2 - 7 } & Estimate & SE & \multicolumn{1}{c}{$\mathrm{t}$} & Estimate & \multicolumn{1}{c}{ SE } & \multicolumn{1}{c}{$\mathrm{t}$} \\
\hline Intercept (+NPI - LOW.NEGATION) & 5.8490 & 0.0308 & 190.0450 & 5.8701 & 0.0329 & 178.2923 \\
MATRIX.VERB (-NPI) & -0.0088 & 0.0119 & -0.7385 & -0.0127 & 0.0157 & -0.8073 \\
+LOW.NEGATION (NEG) & -0.0319 & 0.0145 & -2.1995 & -0.0302 & 0.0192 & -1.5761 \\
trial & -0.0050 & 0.0005 & -9.7793 & -0.0052 & 0.0006 & -9.3646 \\
MATRIX.VERB:LOW.NEGATION & 0.0198 & 0.0207 & 0.9550 & 0.0359 & 0.0273 & 1.3146 \\
\hline
\end{tabular}


Table 6.15: Output of the LME model for first infinitive (schicken) in Experiment 3 lmer (log. RT Matrix. Verb*Low. Negation+segment. length+trial+ (1+Matrix.Verb+segment. length+trial|participant. ID)+(1|stimulus. ID))

\begin{tabular}{lrrrrrr}
\hline & \multicolumn{3}{c}{ criticized model } & \multicolumn{3}{c}{ raw model } \\
\cline { 2 - 7 } & Estimate & \multicolumn{1}{c}{ SE } & \multicolumn{1}{c}{$\mathrm{t}$} & Estimate & \multicolumn{1}{c}{ SE } & \multicolumn{1}{c}{$\mathrm{t}$} \\
\hline Intercept (+NPI -Low.NEGATION) & 5.8420 & 0.0445 & 131.1401 & 5.8563 & 0.0492 & 119.0898 \\
MATRIX.VERB (-NPI) & -0.0177 & 0.0146 & -1.2163 & -0.0147 & 0.0177 & -0.8313 \\
+Low.NEGATION (NEG) & -0.0374 & 0.0163 & -2.2931 & -0.0390 & 0.0201 & -1.9349 \\
segment length & 0.0024 & 0.0039 & 0.6204 & 0.0026 & 0.0043 & 0.6079 \\
trial & -0.0061 & 0.0006 & -9.7544 & -0.0064 & 0.0007 & -9.7246 \\
MATRIX.VERB:Low.NEGATION & 0.0078 & 0.0233 & 0.3363 & 0.0059 & 0.0287 & 0.2064 \\
\hline
\end{tabular}

Table 6.16: Output of the LME model for first infinitive region (zu schicken) in Experiment 3 Imer (log. RT Matrix. Verb*Low. Negation+segment. length+trial+ (1+trial|participant. ID)+(1|stimulus. ID))

\begin{tabular}{lrrrrrr}
\hline & \multicolumn{3}{c}{ criticized model } & \multicolumn{3}{c}{ raw model } \\
\cline { 2 - 7 } & Estimate & \multicolumn{1}{c}{ SE } & \multicolumn{1}{c}{$\mathrm{t}$} & Estimate & \multicolumn{1}{c}{ SE } & $\mathrm{t}$ \\
\hline Intercept (+NPI -LOW.NEGATION) & 6.5306 & 0.0587 & 111.3367 & 6.5454 & 0.0671 & 97.5947 \\
MATRIX.VERB (-NPI) & -0.0163 & 0.0111 & -1.4593 & -0.0123 & 0.0137 & -0.8955 \\
+Low.NEGATION (NEG) & -0.0434 & 0.0136 & -3.1992 & -0.0310 & 0.0168 & -1.8499 \\
Segment length & 0.0031 & 0.0041 & 0.7458 & 0.0029 & 0.0049 & 0.5931 \\
trial & -0.0057 & 0.0006 & -10.3249 & -0.0059 & 0.0006 & -10.0857 \\
MATRIX.VERB:Low.NEGATION & 0.0196 & 0.0194 & 1.0126 & 0.0169 & 0.0239 & 0.7065 \\
\hline
\end{tabular}


Table 6.17: Output of the LME model for first segment of the adverbial (unter) in Experiment 3 Imer (log.RT Matrix.Verb*Low. Negation+segment. length+trial+ (1+trial|participant. ID)+(1|stimulus. ID))

\begin{tabular}{lrrrrrr}
\hline & \multicolumn{3}{c}{ criticized model } & \multicolumn{3}{c}{ raw model } \\
\cline { 2 - 7 } & Estimate & SE & \multicolumn{1}{c}{$\mathrm{t}$} & Estimate & SE & \multicolumn{1}{c}{$\mathrm{t}$} \\
\hline Intercept (+NPI -LOW.NEGATION) & 5.8981 & 0.0366 & 161.1577 & 5.9220 & 0.0412 & 143.5940 \\
MATRIX.VERB (-NPI) & -0.0314 & 0.0125 & -2.5087 & -0.0320 & 0.0157 & -2.0415 \\
+LOW.NEGATION (NEG) & -0.0226 & 0.0153 & -1.4807 & -0.0192 & 0.0192 & -1.0010 \\
Segment length & -0.0029 & 0.0050 & -0.5763 & -0.0030 & 0.0067 & -0.4497 \\
trial & -0.0049 & 0.0005 & -9.6943 & -0.0050 & 0.0006 & -8.9305 \\
MATRIX.VERB:Low.NEGATION & 0.0305 & 0.0218 & 1.3988 & 0.0270 & 0.0273 & 0.9897 \\
\hline
\end{tabular}

Table 6.18: Output of the LME model for second segment of the adverbial (Umständen) in Experiment 3

lmer (log.RT Matrix.Verb*Low. Negation+segment. length+trial+ (1+trial|participant. ID)+(1|stimulus. ID))

\begin{tabular}{lrrrrrr}
\hline & \multicolumn{3}{c}{ criticized model } & \multicolumn{3}{c}{ raw model } \\
\cline { 2 - 7 } & Estimate & \multicolumn{1}{c}{$\mathrm{SE}$} & \multicolumn{1}{c}{$\mathrm{t}$} & Estimate & \multicolumn{1}{c}{$\mathrm{SE}$} & \multicolumn{1}{c}{$\mathrm{t}$} \\
\hline Intercept (+NPI +LOW.NEGATION) & 5.8319 & 0.0411 & 141.9282 & 5.8501 & 0.0435 & 134.3574 \\
MATRIX.VERB (-NPI) & -0.0343 & 0.0171 & -2.0064 & -0.0174 & 0.0221 & -0.7878 \\
-LOW.NEGATION (POS) & 0.0036 & 0.0145 & 0.2452 & 0.0239 & 0.0189 & 1.2682 \\
Segment length & 0.0018 & 0.0027 & 0.6558 & -0.0006 & 0.0032 & -0.1868 \\
trial & -0.0050 & 0.0006 & -8.9633 & -0.0051 & 0.0006 & -8.0745 \\
MATRIX.VERB:LOW.NEGATION & 0.0191 & 0.0209 & 0.9138 & -0.0024 & 0.0269 & -0.0882 \\
\hline
\end{tabular}

Table 6.19: Output of the LME model for the adverbial of the second VP (sofort) in Experiment 3 lmer (log. RT Matrix.Verb*Negation+segment. length+trial+ (1+segment. length+trial|participant. ID)+(1|stimulus. ID $))$

\begin{tabular}{lrrrrrr}
\hline & \multicolumn{3}{c}{ criticized model } & \multicolumn{3}{c}{ raw model } \\
\cline { 2 - 7 } & Estimate & \multicolumn{1}{c}{$\mathrm{SE}$} & \multicolumn{1}{c}{$\mathrm{t}$} & Estimate & $\mathrm{SE}$ & \multicolumn{1}{c}{$\mathrm{t}$} \\
\hline Intercept (-NPI HIGH.NEGATION) & 5.8101 & 0.0374 & 155.1934 & 5.8243 & 0.0409 & 142.3883 \\
MATRIX.VERB (+NPI) & -0.0093 & 0.0175 & -0.5294 & -0.0124 & 0.0219 & -0.5662 \\
NEGATION (No.NEGATION) & -0.0416 & 0.0178 & -2.3413 & -0.0311 & 0.0221 & -1.4069 \\
Segment length & 0.0104 & 0.0037 & 2.7672 & 0.0099 & 0.0041 & 2.4013 \\
trial & -0.0061 & 0.0006 & -10.1179 & -0.0064 & 0.0007 & -9.3876 \\
MATRIX.VERB:NEGATION & 0.0011 & 0.0250 & 0.0460 & 0.0062 & 0.0312 & 0.1988 \\
\hline
\end{tabular}


Table 6.20: Output of the LME model for the adjective of the spillover region (rechtliche) in Experiment 3

lmer $(\log$. RT Matrix. Verb*Negation+segment. length+trial+

$(1+$ Matrix.Verb*Negation | participant. ID $)+(1+$ Negation / stimulus. ID $))$

\begin{tabular}{lrrrrrr}
\hline & \multicolumn{3}{c}{ criticized model } & \multicolumn{3}{c}{ raw model } \\
\cline { 2 - 7 } & Estimate & \multicolumn{1}{c}{ SE } & \multicolumn{1}{c}{$\mathrm{t}$} & Estimate & \multicolumn{1}{c}{ SE } & $\mathrm{t}$ \\
\hline Intercept (+NPI HIGH.NEGATION) & 5.8029 & 0.0432 & 134.4415 & 5.8010 & 0.0473 & 122.5629 \\
MATRIX.VERB (-NPI) & 0.0409 & 0.0166 & 2.4666 & 0.0534 & 0.0202 & 2.6463 \\
NEGATION (No.NEGATION) & 0.0331 & 0.0167 & 1.9786 & 0.0429 & 0.0203 & 2.1128 \\
segment length & 0.0015 & 0.0036 & 0.4012 & 0.0015 & 0.0041 & 0.3642 \\
trial & -0.0059 & 0.0006 & -9.6125 & -0.0060 & 0.0007 & -8.7448 \\
MATRIX.VERB:NEGATION & -0.0459 & 0.0238 & -1.9326 & -0.0401 & 0.0287 & -1.3954 \\
\hline
\end{tabular}




\subsection{Experiment 4: Reconstruction of infinitive-embedding verbs (self-paced reading)}

\subsubsection{Rationale}

The rationale of this experiments makes use of selectional properties of German verbs that embed infinitival verb phrases. Those verbs split into two groups. The majority of embedding verbs select infinitives which are preceded by the particle $z u$ 'to', like the verb versuchen 'try' in (11a). Few verbs, however, embed bare infinitives, like the modal verb müssen 'must' in (11b).

a. Uwe versucht den Zug * ${ }^{(\mathrm{zu})}$ nehmen.

Uwe tries the train to take

'Uwe tries to take the train.'

b. Uwe muss den Zug ( $\left.{ }^{\star} \mathrm{zu}\right)$ nehmen.

Uwe must the train to take

'Uwe must to take the train.'

Each of the embedding verbs may also embed a member of the other group which, in turn, selects an infinitive. The selection requirement, i. e. bare infinitive vs. particle, thereby applies strictly hierarchical from the embedding verb to the directly embedded verb, as indicated by the contrast between the V-final clauses in (12a) and (12b).

a. ..., dass Uwe [[den Zug $\left({ }^{\star} z u\right)$ nehmen] ${ }^{\star}(\mathrm{zu})$ müssen] versucht. that Uwe the train to take to must tries

'... that Uwe tries to must take the train.'7

b. ..., dass Uwe [[den Zug ${ }^{\star}(\mathrm{zu})$ nehmen] $\left({ }^{\star} \mathrm{zu}\right)$ versuchen] muss. that Uwe the train to take to try must

'... that Uwe must try to take the train.'

In V2-clauses, the finite verb moves to the left periphery. If the finite verb is automatically reconstructed after the first infinitive (\#1), the string is temporarily ungrammatical because the first infinitive does not match the requirements of the finite verb as illustrated in (13) and (14).

(13) a. Uwe versucht [[den Zug nehmen] \#1 zu müssen] \#2 versucht. Uwe tries the train take to must

7 Clearly, the meaning of this combination is quite unusual. Assume that Uwe intentionally creates a situation, in order to set himself under pressure, in which he has no choice but to take a certain train. 
b. * Uwe versucht [[den Zug nehmen] versucht] ... Uwe tries the train take

(14) a. Uwe muss [[den Zug zu nehmen] \#1 versuchen] \#2 muss. Uwe must the train to take try

b. * Uwe muss [[den Zug zu nehmen] muss] ... Uwe must the train to take

\subsubsection{Method}

\subsubsection{Participants and procedure}

Participants and procedure are identical to Experiment 3 because both experiments have been combined in one experimental run.

\subsubsection{Materials}

Materials consisted of 8 experimental items interspersed with 58 fillers (32 from Experiment 3) resulting in 66 stimuli per participant. All stimuli consisted of an introductory context of 1-2 sentences, a declarative target sentence and a comprehension question (50\% polar interrogatives and $50 \%$ constituent questions).

An example item is given in (15). All target clauses have an adverbial in the sentence-initial position. The V2-position was filled with an infinitive-embedding verb which varied according to the experimental condition MATRIX.VERB, either selecting an infinitive with a particle (PARTICLE), like beabsichtigen 'intend' in (15b), or selecting a bare infinitives (BARE) like müssen 'must' in (15c). In both conditions, the identical ditransitive non-finite VP followed the V2-position. The infinitive of this VP, zu navigieren 'to navigate', was always preceded by the infinitive particle $z u$ 'to'. Consequently, the sentence could be a well-formed structure only in the PARTICLE condition but not in the BARE condition as indicated by the starred reconstruction position (\#1) in (15c). Only after a 2-segment adverbial, like am Anfang 'in the beginning', a second infinitive was presented, which corresponded to the selectional requirements of the respective matrix verbs rendering all items well-formed. A 6-segment embedded clause followed the infinitive to detect potential spillover effects.

(15) a. ConTEXT:

Ein Bauarbeiter hat den Arbeitgeber gewechselt. Hier müssen nun die Fahrzeuge jeden Abend in die engen Garagen geparkt werden.

'A construction worker changed his employer. Here, the vehicles now have to pulled into the narrow garages every evening.' 
b. PARTICLE

Logischerweise beabsichtigt der Bauarbeiter den Lastwagen logically intends the construction worker the truck in die Garage zu navigieren \#1 am Anfang erst zu lernen, damit into the garage to navigate at the beginning first to learn so that das teure Fahrzeug heil bleibt. the expensive vehicle undamaged remains

'Naturally, the construction worker intends to learn how to navigate the truck into the garage first, so that the expensive vehicle will remain undamaged.'

c. BARE

Logischerweise muss der Bauarbeiter den Lastwagen in die logically must the construction worker the truck into the Garage zu navigieren $\# 1$ am Anfang erst lernen, damit das garage to navigate at the beginning first to learn so that teure Fahrzeug heil bleibt.

the expensive vehicle undamaged remains

'Naturally, the construction worker must learn how to navigate the truck into the garage first, so that the expensive vehicle will remain undamaged.'

d. COMPREHENSION QUESTION:

Von welchem Fahrzeug war hier die Rede?

'What kind of vehicle was talked about?'

correct answer = von einem Laster 'about a truck' wrong answer = von einem Bagger 'about an excavator'

According to the V2-Reconstruction Hypothesis, the finite verbs will be automatically reconstructed and interpreted after the first infinitive navigieren. In the BARE condition, however, the infinitive does not match the selectional requirements of the finite matrix verb. Hence, I predict longer reading times for the BARE condition at this segment.

The low number of items is a consequence of the low number of verbs selecting a bare infinitive overall. I could not come up with more verbs that could be paired with a canonical cluster verb that is either synonymous or at least replaceable in the same context. The verb pairs of the materials are given Table 6.21, all experimental items are given in the online appendix. 
Table 6.21: Pairs of cluster verb in Experiment 4

\begin{tabular}{|c|c|}
\hline BARE & PARTICLE \\
\hline muss 'must' & beabsichtigt 'intends' \\
\hline soll 'should' & probiert 'tries' \\
\hline darf 'is allowed' & gedenkt 'intends' \\
\hline möchte 'wants' & plant 'plans' \\
\hline lässt 'lets’ & intendiert 'intends' \\
\hline kommt 'comes to' & versucht 'tries' \\
\hline kann 'can' & verlangt 'demands' \\
\hline sieht 'sees' & verpflichtet 'obligates' \\
\hline
\end{tabular}

\subsubsection{Data analysis}

Prior to the analysis, all reading times larger than 2 seconds $(n=43)$ have been excluded ( $0.06 \%$ of the data). The participants' accuracy in response to the comprehension questions ranged from 63-100\% (mean 87\%). No participant was excluded from the analysis but all trials with a false response to the comprehension question were excluded ( $13 \%$ of the data). The statistical handling of the data was identical to the procedure described for Experiment 2.

\subsubsection{Results}

A graphical summary of the reading times of the region of interest, ranging from the V2-position until the spillover region, is given in Figure 6.6. On the subject determiner der 'the', the model revealed longer reading times for the PARTICLE condition $(t=-2.1779)$. On the first infinitive navigieren 'navigate' the analysis indicated longer reading times for the PARTICLE condition only in the first model. After model criticism, the effect decreased below significance $(t=-1.7229)$ indicating that the effect was mostly driven by extreme values. The analysis revealed longer reading times for the BARE condition only on the first adverbial segment $a m(t=2.1286)$ but no effect on the second segment Anfang. The analysis of the aggregated reading times for the region am Anfang 'at the beginning' indicated longer reading times for the BARE condition $(t=2.8873)$. On the second infinitive lernen, the analysis revealed longer reading times for the PARTICLE condition $(t=-2.3438)$. No effects could be detected on the other segments. The exact model outputs of the analyses are given in Tables 6.22 to 6.26. 




Figure 6.6: Mean reading times in from the V2-position until the spillover region in Experiment 4 (95\% Cls)

\subsubsection{Discussion}

In line with the predictions above, the results indicated longer reading times for the BARE condition on the two segments following the first possible reconstruction site of the matrix verb am Anfang 'at the beginning', i. e. the dark-gray area in Figure 6.6. I assume that with the encounter of the infinitive navigieren 'navigate' the matrix verb is automatically reconstructed and interpreted. In the BARE condition, the resulting representation is ill-formed because the infinitive is accompanied by the infinitive particle $z u$ 'to', which violates the selectional requirements of matrix verbs like müssen 'must' which select a bare infinitive. The response to this temporary ungrammaticality is reflected by the longer reading times on the two adverb segments am Anfang 'at the beginning'. Note that an alternative explanation based on an incremental interpretation would predict the opposite effect. Assume that incoming material is integrated in the parse strictly from left to right without resorting to reconstruction. In the PARTICLE condition, the parse could be completed after the first infinitive navigieren. Hence the encounter of the adverbial am Anfang would indicate that the structure is not yet complete which should trigger a reanalysis reflected by prolonged reading times. In the BARE condition, on the other hand, the first infinitive does not match the selectional requirements of the matrix verb. Therefore, the parse could not be completed at this point. The encounter of the adverbial does not trigger a reanalysis but only continues the current structure. In sum, under a strictly incremental approach, we would expect longer reading times in the PARTICLE condition, contrary to the facts. 
The results indicated longer reading times in the PARTICLE condition at three segments, i. e. the light-gray areas in Figure 6.6. Two of them are probably spillover effects caused by the directly preceding elements: The effect on the subject determiner is most likely caused by the previous segment, which consisted of the different lexical matrix verbs varying according to the experimental conditions. The effect on the second infinitive lernen might also be interpreted as a spillover effect. Remember that in the PARTICLE condition, the infinitive was preceded by the particle $z u$ 'to' whereas, in the BARE condition, the infinitive was adjacent to the preceding adverbial. Only the tendency on the first infinitive navigieren 'navigate' is certainly a distant effect related to the matrix verb. Considering the linear distribution of these contrasts, I assume that all three effects stem from one underlying mechanism, i. e. they reflect lexical (re)activation processes. Initially, lexical access of the verbs in the PARTICLE condition is more demanding than for the verbs in the BARE condition which induces longer reading times at the first encounter of the verbs, i.e. on the segment following the V2-position. According to the V2-Reconstruction Hypothesis, the matrix verb is reactivated at the segments directly preceding its potential base position, i. e. at the two infinitives navigieren and lernen (see also the results of experiments 2 and 3). At these position, the lexical reactivation of the verbs of the PARTICLE condition is also more costly; again reflected by locally prolonged reading times. Additionally, this explanation matches the temporal profile of the intended experimental effect. The mismatch effect of the infinitive selection directly follows the lexical reactivation of the matrix verb at the first infinitive, because evaluation of selectional requirements depends on the lexical information.

In sum, the experiment yielded the predicted results, i. e. a mismatch effect directly following a potential reconstruction site, thereby supporting the V2-Reconstruction Hypothesis. Additionally, the results indicate that lexical reactivation precedes the evaluation of selectional requirements of embedding verbs at their reconstruction sites.

Table 6.22: Output of the LME model for determiner of the subject (der) in Experiment 4 lmer(log. RT Matrix.Verb+trial+(1| participant. ID)+(1|stimulus. ID))

\begin{tabular}{lrrrrrr}
\hline & \multicolumn{3}{c}{ criticized model } & \multicolumn{3}{c}{ raw model } \\
\cline { 2 - 7 } & Estimate & SE & $\mathrm{t}$ & Estimate & \multicolumn{1}{c}{ SE } & \multicolumn{1}{c}{$\mathrm{t}$} \\
\hline Intercept (PARTICLE) & 5.7966 & 0.0392 & 147.9671 & 5.8143 & 0.0410 & 141.8559 \\
MATRIX.VERB (BARE) & -0.0461 & 0.0212 & -2.1779 & -0.0503 & 0.0262 & -1.9211 \\
trial & -0.0042 & 0.0006 & -6.8288 & -0.0048 & 0.0008 & -6.3209 \\
\hline
\end{tabular}


Table 6.23: Output of the LME model for the first infinitive (navigieren) in Experiment 4 lmer (log. RT Matrix.Verb+segment. length+trial+(1+segment. length+trial | participant. ID $)+(1 \mid$ stimulus. ID) $)$

\begin{tabular}{lrcrrrr}
\hline & \multicolumn{3}{c}{ criticized model } & \multicolumn{3}{c}{ raw model } \\
\cline { 2 - 7 } & Estimate & \multicolumn{1}{c}{ SE } & \multicolumn{1}{c}{$\mathrm{t}$} & Estimate & \multicolumn{1}{c}{ SE } & \multicolumn{1}{c}{$\mathrm{t}$} \\
\hline Intercept (PARTICLE) & 5.6763 & 0.0940 & 60.3957 & 5.6235 & 0.0855 & 65.7551 \\
MATRIX.VERB (BARE) & -0.0397 & 0.0230 & -1.7229 & -0.0715 & 0.0288 & -2.4802 \\
segment.length & 0.0260 & 0.0099 & 2.6165 & 0.0361 & 0.0093 & 3.8913 \\
trial & -0.0055 & 0.0009 & -6.1586 & -0.0059 & 0.0010 & -5.7025 \\
\hline
\end{tabular}

Table 6.24: Output of the LME model for the first adverb segment (am) in Experiment 4 lmer (log. RT Matrix.Verb+segment. length+trial+(1+trial|participant. ID)+ (1|stimulus. ID))

\begin{tabular}{lrrrrrr}
\hline & \multicolumn{3}{c}{ criticized model } & \multicolumn{3}{c}{ raw model } \\
\cline { 2 - 7 } & Estimate & \multicolumn{1}{c}{$\mathrm{SE}$} & \multicolumn{1}{c}{$\mathrm{t}$} & Estimate & \multicolumn{1}{c}{$\mathrm{SE}$} & \multicolumn{1}{c}{$\mathrm{t}$} \\
\hline Intercept (PARTICLE) & 5.7774 & 0.0460 & 125.6477 & 5.8078 & 0.0543 & 106.8798 \\
MATRIX.VERB (BARE) & 0.0490 & 0.0230 & 2.1286 & 0.0454 & 0.0275 & 1.6494 \\
segment.length & 0.0457 & 0.0120 & 3.8110 & 0.0409 & 0.0154 & 2.6540 \\
trial & -0.0045 & 0.0009 & -4.7716 & -0.0051 & 0.0009 & -5.7851 \\
\hline
\end{tabular}

Table 6.25: Output of the LME model for the second 2-segment adverb region (am Anfang) in Experiment 4

$\operatorname{lmer}(\log$. RT Matrix.Verb+segment. length+trial+(1|participant. ID)+(1|stimulus. ID))

\begin{tabular}{lrrrrrr}
\hline & \multicolumn{3}{c}{ criticized model } & \multicolumn{3}{c}{ raw model } \\
\cline { 2 - 7 } & Estimate & \multicolumn{1}{c}{$\mathrm{SE}$} & \multicolumn{1}{c}{$\mathrm{t}$} & Estimate & \multicolumn{1}{c}{$\mathrm{SE}$} & \multicolumn{1}{c}{$\mathrm{t}$} \\
\hline Intercept (PARTICLE) & 6.5201 & 0.1117 & 58.3604 & 6.5371 & 0.1150 & 56.8254 \\
MATRIX.VERB (BARE) & 0.0571 & 0.0198 & 2.8873 & 0.0382 & 0.0232 & 1.6479 \\
segment.length & 0.0065 & 0.0107 & 0.6023 & 0.0067 & 0.0111 & 0.6084 \\
trial & -0.0051 & 0.0006 & -8.7960 & -0.0051 & 0.0007 & -7.5005 \\
\hline
\end{tabular}

Table 6.26: Output of the LME model for the second infinitive (lernen) in Experiment 4 lmer (log.RT Matrix.Verb+segment. length+trial+(1+Matrix.Verb+trial|participant. ID)+ (1|stimulus. ID))

\begin{tabular}{lrcrrrr}
\hline & \multicolumn{3}{c}{ criticized model } & \multicolumn{3}{c}{ raw model } \\
\cline { 2 - 7 } & Estimate & \multicolumn{1}{c}{$\mathrm{SE}$} & $\mathrm{t}$ & Estimate & \multicolumn{1}{c}{$\mathrm{SE}$} & \multicolumn{1}{c}{$\mathrm{t}$} \\
\hline Intercept (PARTICLE) & 5.8328 & 0.0875 & 66.6348 & 5.8028 & 0.1248 & 46.5084 \\
MATRIX.VERB (BARE) & -0.0646 & 0.0275 & -2.3438 & -0.0529 & 0.0380 & -1.3938 \\
segment.length & 0.0108 & 0.0073 & 1.4781 & 0.0160 & 0.0115 & 1.3930 \\
trial & -0.0060 & 0.0009 & -6.5301 & -0.0071 & 0.0011 & -6.1781 \\
\hline
\end{tabular}




\subsection{Experiment 5: Verb reconstruction and word order preferences (self-paced reading)}

\subsubsection{Rationale}

The rationale of this experiment connects closely to the findings about thematic processing, which have been discussed in Section 5.3.1. There, I have summarized that effects related to the thematic structure of the verb are only found at the assumed base position of the finite verb, irrespective whether the lexical verb specifying the thematic structure of the clause appears in the V2-position or in its base position. Previous experiments, however, included additional factors that influence thematic processing such as case-ambiguity, two animate arguments, and dative case. In this experiment, $\mathrm{we}^{8}$ investigate the influence of the thematic information of the verb in V2-position on the processing of the arguments in relatively unmarked structures. We contrast the experiencer-first preference of experiencer object (EO) verbs with the subject-first preference which assumably holds for the default processing routine as well as non-experiencer verbs (non-Exp). The abstract schematics in (16)-(18) illustrate the linear ordering of the critical configurations. Consider (16), if the V2-position is occupied by an auxiliary like haben 'have', no information about the thematic roles of the arguments is available to the processor by the time the arguments are processed. The processor must rely on the default subject-first preference until it reaches the lexical verb. Hence, we expect that the subject<object order is processed faster than the object $<$ subject order, as indicated by the pointing glyph.

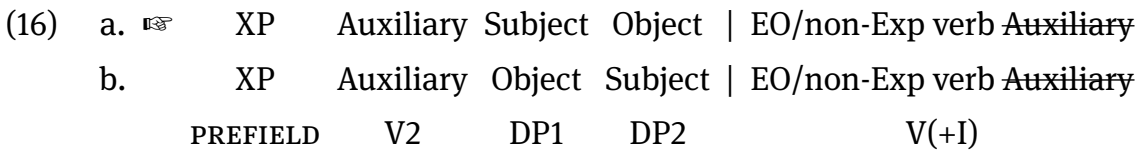

The same pattern is expected for non-Exp verbs. If the thematic information of the lexical verb influences argument processing, we expect a preference for the subject $<$ object order in (17). If the finite verb is only interpreted in its base position, we expect the same effect although caused by the default processing routine analogously to the V2-auxiliary cases in (16).

8 This experiment presents collaborative work with Anne Temme. I will therefore use we in this chapter purposely. 


\begin{tabular}{lcccc|c} 
a. & XP & non-Exp verb Subject & & Object $_{\text {AGEME }}$ & non Exp \\
b. & XP & non-Exp verb & Object $_{\text {THEME }}$ & Subject $_{\text {AGENT }}$ & non Exp verb \\
& PREFIELD & V2 & DP1 & DP2 & V $(+\mathrm{I})$
\end{tabular}

Clauses with an experiencer object verb in the V2-position, however, constitute critical test cases. There, the experiencer-first preference conflicts with the subjectfirst preference. Objects of experiencer verbs are more likely to precede the subject, than objects of non-experiencer verbs, as experimentally confirmed by Temme \& Verhoeven (2016: 783-790). We assume that the experiencer-first preference also affects online-processing directly in such a way that the object<subject order is processed faster, as indicated in (18). Crucially, this only holds under the assumption that the information about the thematic roles encoded in a verb in V2-position is immediately activated at its surface position, where it precedes its arguments. Under the V2-Reconstruction Hypothesis, however, we expect that the lexical meaning of the verb in V2-position, including the information about the thematic roles, is only interpreted in its base position, which follows its arguments. Thus, initially, the experiencer object structures in (18) will be processed with the same default subject<object preference that we predict for the V2-auxiliary structures in (16). We expect that verb-type-specific effects will occur only right-adjacent to the second argument in transitive structures, similar to the results of Scheepers et al. (2000).

$$
\begin{array}{lccccc|c}
\text { a. } & \text { XP } & \text { EO-verb Subject } & & \text { Object }_{\text {EXP }} & \text { EO verb } \\
\text { b. } & \text { XP } & \text { EO-verb } & \text { Object }_{\text {EXP }} & \text { Subject }_{\text {STIM }} & \text { EO-verb } \\
& \text { PREFIELD } & \text { V2 } & \text { DP1 } & \text { DP2 } & \text { V(+I) }
\end{array}
$$

Additionally, two hypotheses apply to the V-final condition, corresponding to scheme (16) above. First, thematic role assignment may apply anticipatorily: In absence of a lexical verb that specifies the thematic roles, the processor assigns thematic roles by default, maybe guided by properties of the arguments such as animacy and case (see Bornkessel \& Schlesewsky 2006a). If, however, two verbs which assign different thematic roles follow the identical argument configuration, we expect that at least for one verb the roles have to be reassigned, which should be reflected in increased processing costs. Alternatively thematic role assignment may be delayed in absence of an assigner. Following this path the assignment of thematic roles remains underspecified until the lexical verb is encountered. In principle, both assignment procedures are compatible with the V2-Reconstruction Hypothesis and an incremental processing hypothesis. However, we assume the delayed assignment to be the more economic variant if applied to V2-cases. 
Otherwise, the processor would assign incorrect thematic roles by default even though the information about the assigner would, in principle, be available.

To sum up, this experiment uses three factors to diagnose the influence of thematic information of lexical verbs on on-line processing. If the lexical verb is presented late, in its base position, as in (16), the verb cannot influence the processing of the arguments and the default processing routine must take place, preferring subject $<$ object order. If, however, the lexical verb appears in V2-position, the information about the thematic roles is principally available. Under a strict incremental processing hypothesis, we expect that the information about the thematic roles will decrease the subject-first preference for experiencer object verbs immediately after the encounter of the lexical verb. In contrast, under the V2-Reconstruction Hypothesis, we expect that the processing of the arguments always proceeds according to the default mechanism because the lexical meaning of the verb in V2-position will only be interpreted in its base position. Thus, we expect an interaction of verb type and argument order in any case but two different temporal profiles according to respective hypotheses.

\subsubsection{Method}

\subsubsection{Participants}

We tested 48 participants (age 19-50 years, mean 24 years; 7 male; 4 left-handed), all self-declared German native speakers ( 6 bilinguals) and students of the University of Cologne. Participants either received course credits or a reimbursement of $4 €$.

\subsubsection{Procedure}

The self-paced reading procedure was almost identical to Experiment 3 above. The only difference was that the target sentences were not presented strictly word per word but also larger phrases were presented at once, as indicated for the material below.

The context was presented as one text block. The presentation of the target sentence began with a fixation cross and conformed to the centered self-paced reading paradigm (Just et al. 1982) in which the segments were presented noncumulatively in a stationary window, i. e. participants saw only one segment at a time at the center of the screen and had no visual cues that would allow them to predict the length of the sentences. Participant moved through the segments at their own pace by pressing the space bar. Each item contained a comprehension question to control whether participants paid attention to the task. Answers 
to the comprehension questions were presented in the bottom left and right of the screen and were chosen by pressing the ' $\mathrm{d}$ ' or ' $\mathrm{k}$ ' key on a German keyboard respectively. After each response the participants saw a feedback message whether their response was correct or not. Participants were instructed to read the sentences and answer the question as fast as possible in order to give correct responses.

The procedure was programmed in the python experiment suite PsychoPy (Peirce 2007) and run on a Windows PC in a psycholinguistics lab. The experimental stimuli have been randomized according to the Latin square design, such that each participant saw each of the 32 items in exactly one of the 6 experimental conditions. The position of the correct answer to the comprehension question (left or right) was balanced across the items. The total list of stimuli (experimental items plus fillers) were automatically randomized by the experiment software. Experiments took approximately 20 minutes.

\subsubsection{Materials}

The materials consisted of 32 experimental items interspersed with 32 filler items resulting in 64 stimuli per participant. The 32 filler items included two sets of control structures with 8 items each, which are explicated below. All stimuli consisted of a context of 1-2 sentences, a declarative target sentence and a comprehension question (50\% polar interrogatives and 50\% constituent questions).

The target sentences varied in a $2 \times 2 \times 2$ design with the factors V-TyPE, V-Position, and Word ORDER. An example item is given in (19). The context sentences, such as (19a), introduced two concepts which are supersets to the subject and object of the target sentence, such as traditional methods for the woven coat, and people who work with bees for the beekeeper. This unspecific introduction should avoid increased reading times especially for information structurally marked object<subject (OS) orders (see Weskott 2003: 62-76). The target sentences were presented in segments as indicated in (19b). The sentence-initial segment was a sentence adverbial. By filling the prefield, we ensured that all arguments would follow the V2-position. The V2-position (C) was either filled by the auxiliary hat 'has' in the V-FINAL conditions such as (19b), or by the lexical verb in the simple past form, such as verblüfte 'baffled', in the V2 conditions, see (19d). The subsequent positions of DP1 and DP2 are separated by a high temporal adverb, such as letztens 'recently'. ${ }^{9}$ The two DP-positions are filled by the subject der gewebte Mantel 'the woven coat' and the object den vorsichtigen Imker 'the cautious beekeeper' corresponding to the subject<object (SO) and OS condition

9 See Frey \& Pittner (1998) or Frey (2003) for an overview of base positions of adverbials in German. 
respectively. The nominative subject was always inanimate and the accusative object was always animate. Both nouns were always masculine singular such that they exhibit unambiguous case marking in German. A low process-related adverbial, such as total 'totally', separated the lower argument from the clausefinal position (V) which was filled only in the V-FINAL condition, namely by the participle of the lexical verb, such as verblüfft 'baffled' in (19b). The two clauseinternal adverbials have been inserted to separate the critical DP-regions and the clause-final verb so that effects of one region would not immediately spill over onto the next region. All conditions contained an embedded clause as a final spillover region, which was divided into four segments: a subordination, a definite DP, and two segments that showed larger variation between items in order to create meaningful continuations for all scenarios. The lexical verb was either an experiencer object verb in the EXPERIENCER conditions, such as verblüffen 'baffle' in (19b-19e), or a non-experiencer verb in the NON-EXPERIENCER conditions, such as schützen 'protect' in (19f-19g). The non-experiencer verbs do not form a natural class, however, many of them are causative verbs. They have in common that they are non-psych verbs which take inanimate subjects (stimulus) and animate objects (theme/patient). In some of the items, the low adverb and the spillover regions differed between the two verb classes in order to maintain plausibility.

a. Context:

Traditionelle Methoden sind immer noch das Mittel der Wahl für Leute, die mit Bienen arbeiten.

'Traditional methods are still the means of choice for people who work with bees.'

b. EXPERIENCER-V-FINAL-SO

Offenbar | hat | der gewebte Mantel | letztens | den vorsichtigen apparently has the woven coat recently the cautious PREFIELD C DP1 HIGHADV DP2 Imker | total | verblüfft, | obwohl | die Bienen | ziemlich beekeeper totally baffled although the bees quite LOWADV V $\quad$ SPILL1 SPILL2 $\quad$ SPILL3

angriffslustig | waren.

aggressive were SPILL4

'Apparently, the woven coat recently baffled the cautious beekeeper totally although the bees were quite aggressive.' 
C. EXPERIENCER-V-FINAL-OS

Offenbar hat den vorsichtigen Imker letztens der gewebte Mantel apparently has the cautious beekeeper recently the woven coat total verblüfft, obwohl die Bienen ziemlich angriffslustig waren. totally baffled although the bees quite aggressive were

d. EXPERIENCER-V2-SO

Offenbar verblüffte der gewebte Mantel letztens den vorsichtigen apparently baffled the woven coat recently the cautious Imker total, obwohl die Bienen ziemlich angriffslustig waren. beekeeper totally although the bees quite aggressive were

e. EXPERIENCER-V2-OS

Offenbar verblüffte den vorsichtigen Imker letztens der gewebte apparently baffled the cautious beekeeper recently the woven Mantel total, obwohl die Bienen ziemlich angriffslustig waren. coat totally although the bees quite aggressive were

f. NON-EXPERIENCER-V-FINAL/V2-SO

Offenbar hat/ schützte der gewebte Mantel letztens den vorsichtigen apparently has/protected the woven coat recently the cautious Imker genug geschützt/ $\varnothing$, obwohl die Bienenziemlichangriffslustig beekeeper enough protected althoughthebees quite aggressive waren.

were

'Apparently, the woven coat recently protected the cautious beekeeper sufficiently although the bees were quite aggressive.'

g. NON-EXPERIENCER-V-FINAL/V2-OS

Offenbar hat/ schützte den vorsichtigen Imker letztens der apparently has/ protected the cautious beekeeper recently the gewebte Mantel genug geschützt/ $\varnothing$, obwohl die Bienen ziemlich woven coat enough protected although the bees quite angriffslustig waren.

aggressive were

h. COMPEHENSION QUESTION:

Werden neue Methoden bevorzugt bei der Arbeit mit Bienen?

'Are novel methods preferred in beekeeping?'

correct answer $=$ Nein 'No' $\quad$ wrong answer $=J a$ 'Yes'

The factor V-TyPE differs from the other two factors in so far as the individual lexical verbs are fixed with respect to the different lexicalizations. Each EO-verb was paired with a corresponding non-experiencer verb, such as verblüffen 'baffle' with 
schützen 'protect'. Moreover, the number of suitable verb pairs is rather restricted so that we only used 16 different verb pairs in this experiment. Each of these pairs appeared twice in the experimental material, although with different accompanying lexical material. However, we ensured that each participant saw each lexicalization and each lexical verb of the pair only once during the experiment, e. g. the EXPERIENCER verb with lexicalization A and the NON-EXPERIENCER verb with lexicalization B. Apart from that, the factors varied according to a Latin square design.

The Agentive control structures, illustrated in (20), consisted of the same number and types of segments as the experimental items in (19). In contrast to the experimental items, they contained verbs that select an agent, such as zerreißen 'rip' and more prototypical arguments: The nominative subject was animate and the accusative object was inanimate. Like in the experimental items, the DPs were always definite, masculine, singular and contained an adjectival modifier. These control structures were constructed only in the canonical SO order. They provide a baseline for a prototypical subject-first preference and allow to gauge whether the non-prototypical animacy properties of the experimental items led to a deviation of this preference.

(20) AgEnTive-controls

a. Context:

Die Arbeiter auf der Baustelle leiden oft darunter, dass zu wenig Material für die anstehenden Arbeiten vorhanden ist.

'The workers on the construction site often suffer from the fact that too little material for the upcoming work is available.'

b. V-FINAL-SO

Deswegen | hat | der dicke Maler | heute | den alten Lappen | hence has the fat painter today the old rag kurzerhand | zerissen, | damit | die Lehrlinge | beide etwas quickly ripped so that the apprentices both something zum Abwischen | hatten.

to wipe had

'Hence the fat painter ripped up the old rag today so that both apprentices had something to wipe.'

c. V2-SO

Deswegen zeriss der dicke Maler heute den alten Lappen kurzerhand, hence ripped the fat paintertoday the old rag quickly damit die Lehrlinge beide etwas zum Abwischen hatten. so that the apprentices both something to wipe had 
d. COMPREHENSION QUESTION:

Haben die Bauarbeiter zu wenig Material?

'Did the construction workers lack material?'

correct answer $=J a$ 'Yes' $\quad$ wrong answer $=$ Nein 'No'

The Configurational control structures, illustrated in (21), also consisted of the same number and types of segments, as the experimental items. These control structures contain configurational verbs, such as umgeben 'surround', and two inanimate arguments. This verb class resembles experiencer object verbs in two respects, which makes them useful control structures: First, they take inanimate nominative subjects, and second, they also show a relatively unmarked object $<$ subject order. However, the unmarked object $<$ subject order depends on the definiteness of the subject. Therefore, the nominative subject of these verbs was always an indefinite DP. The accusative object, however, was always definite. Both DPs were masculine singular and contained an adjectival modifier. Like the experimental items, these control structures varied according to the two factors V-POSITION and WORD ORDER as shown in (21). All stimuli are given in the online appendix.

(21) Configurational-controls

a. ConteXt:

Die Archäologen untersuchen die auffälligen Steinformationen in der Nähe des alten Klosters. Etwas war hier besonders.

'The archaeologists investigate the peculiar stone formation in the vicinity of the old monastery. Something was special here.'

b. V-FINAL-SO

Offenbar | hat | ein hoher Schutzwall | damals | den weiten apparently has a high protective barrier back then the large Acker | vollständig | umgeben, | damit | die Ernte | in unruhigen field completely surrounded so that the harvest in turbulent Zeiten | verteidigt werden konnte.

times protected be could

'Apparently, a large protective barrier surrounded the large field entirely back then so that the harvest could be protected in turbulent times.'

c. V-FINAL-OS

Offenbar hat den weiten Acker damals ein hoher Schutzwall apparently has the large field back then a high protective barrier 
vollständig umgeben, damit die Ernte in unruhigen Zeiten completely surrounded so that the harvest in turbulent times verteidigt werden konnte.

protected be could

d. V2-SO

Offenbar umgab ein hoher Schutzwall damals den apparently surrounded a high protective barrier back then the weiten Acker vollständig, damit die Ernte in unruhigen Zeiten large field completely so that the harvest in turbulent times verteidigt werden konnte.

protected be could

e. $\mathrm{V} 2-\mathrm{OS}$

Offenbar umgab den weiten Acker damals ein hoher apparently surrounden the large field back then a high Schutzwall vollständig, damit die Ernte in unruhigen Zeiten protective barrier completely so that the harvest in turbulent times verteidigt werden konnte. protected be could

f. COMPREHENSION QUESTION: Umgab der Schutzwall nur den Marktplatz?

'Did the protective barrier surround the market square?' correct answer $=$ No 'No' $\quad$ wrong answer $=J a$ 'Yes'

\subsubsection{Data analysis}

We removed all data points with reading times larger than 3 seconds $(0.018 \%$ of the data). The participants' accuracy in response to the comprehension questions ranged from 78-97\% (mean $90 \%$ ). No participant was excluded but we dismissed all trials of the experimental items with a falsely answered comprehension question ( $8.4 \%$ of the data). The statistical handling of the data was identical to the procedure described for Experiment 2.

The statistical analysis proceeded in four steps: The first analysis covered only the initial segments from the V2-position until the high adverb. The V-FINAL conditions of both verb types are identical because for both verbs the auxiliary hat 'has' appears in the V2-position. Hence, we analyzed this region with a $3 \times 2$ analysis, featuring three types of verbs in the V2-position, auxiliaries, EXPERIENCER and NON-EXPERIENCER and the two levels of WORD ORDER, SO and OS. In a second step, we analyzed the clause-final verb and the spillover region. This analysis was carried out with two separate models for the V2 and the V-FINAL condition 
respectively. In the third step, we compared the SO conditions with the AGENTIVE controls. In the fourth step, we analyzed the confIGURATIONAL controls.

\subsubsection{Results and Discussion}

\subsubsection{Experimental items}

\subsection{Main clause}

A graphical summary of the reading times of the main clause segments is given in Figure 6.7. On the DP1-segment, the analysis revealed that the AUXILIARY conditions showed significantly shorter reading times than the EXPERIENCER Condition $(t=3.7550)$, and than the NON-EXPERIENCER Condition $(t=2.4896)$. These differences are robust for both WORD ORDER conditions. Whereas the EXPERIENCER condition showed numerically the longest reading times, the contrast to the NON-EXPERIENCER condition is non-significant. On the high adverb letztens, we detected a significant contrast between the EXPERIENCER-SO and the NONEXPERIENCER-SO condition ( $t=2.0207)$ with longer reading times for the latter. Additionally, the model also revealed a significant interaction $(t=-2.1677)$, which indicates that the SO-order caused longer reading times in the NON-EXPERIENCER condition, whereas the opposite holds for the EXPERIENCER condition and the AUXILIARY condition, in which the OS-order led to longer reading times. On the DP2-segment, the analysis revealed a significant contrast of WORD ORDER for the EXPERIENCER verbs $(t=4.5269)$ with longer reading times for the OS-order. Additionally, the interaction terms indicate that the WORD ORDER effect is smaller for the AUXILIARY and the NON-EXPERIENCER condition. Subsequent analyses revealed that reading times for the OS condition are significantly longer in the AUXILIARY condition too, whereas they are only numerically longer in the NONEXPERIENCER condition and did not reach significance. On the low adverb total, we found a significant contrast between the NON-EXPERIENCER-SO and the AUXILIARY-SO condition ( $t=-2.1027)$ with longer reading times for the former. The exact model outputs of these analyses are given in Tables 6.27 to 6.30.

Note that for the V-FINAL conditions (AUXILIARY), which we consider the baseline with respect to default processing of arguments, we have found an effect of WORD ORDER only on a single segment: On the DP2-segment, reading times for the OS condition were longer than in the SO condition $(t=3.0534)$, see Table 6.31.

\subsection{Verb + Spillover}

The reading times for the clause-final verb and the following spillover region are displayed in Figure 6.8. On the clause-final verb, the analyses revealed the shortest 


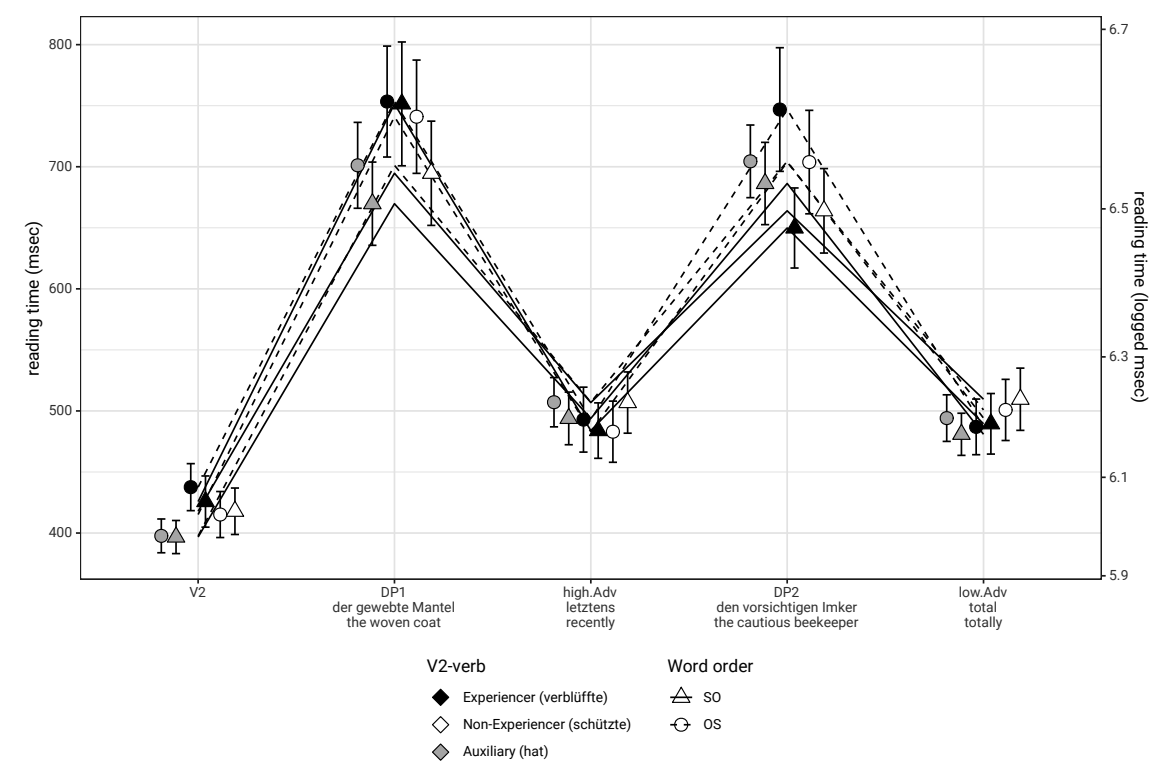

Figure 6.7: Mean reading times for the initial part of Experiment 5 (95\% Cls)

reading times for the EXPERIENCER-SO conditions with significant contrasts to the NON-EXPERIENCER $(t=2.0361)$ and to the OS condition $(t=2.3428)$. Within the NON-EXPERIENCER condition the WORD ORDER difference is non-significant, see Table 6.32.

The respective analyses of the spillover region of the V2 condition and the VFINAL condition indicated only non-significant tendencies for segment 1-3 and a significant contrast only on the final segments, see Tables 6.33 to 6.36. We summarized the reading times for spillover segment 1 and 2, as well as for spillover segment 3 and 4 to obtain a more robust pattern, as displayed in Figure 6.9. In the V2 subset (small icons), we found a significant interaction of V-TYPE and WoRD ORDER $(t=-2.0100)$ in the first region, indicating that OS-order causes longer reading times for the EXPERIENCER verbs, whereas OS-order causes shorter reading times for NON-EXPERIENCER-verbs. In the final region, the analysis revealed two main effects, with longer reading times for EXPERIENCER-verbs ( $t=3.3371$ ) and OS-order $(t=2.0726)$. In the V-FINAL subset (large icons), no effect could be found on the first spillover region. In the final region, however, the analysis revealed a significant contrast of V-TYPE $(t=3.8937)$ indicating that the EXPERIENCER-SO condition showed longer reading times than the NON-EXPERIENCER-SO condition, see Tables 6.37 to 6.39 . 




Figure 6.8: Mean reading times for the clause-final verb and the spillover region in Experiment $5(95 \% \mathrm{Cls})$

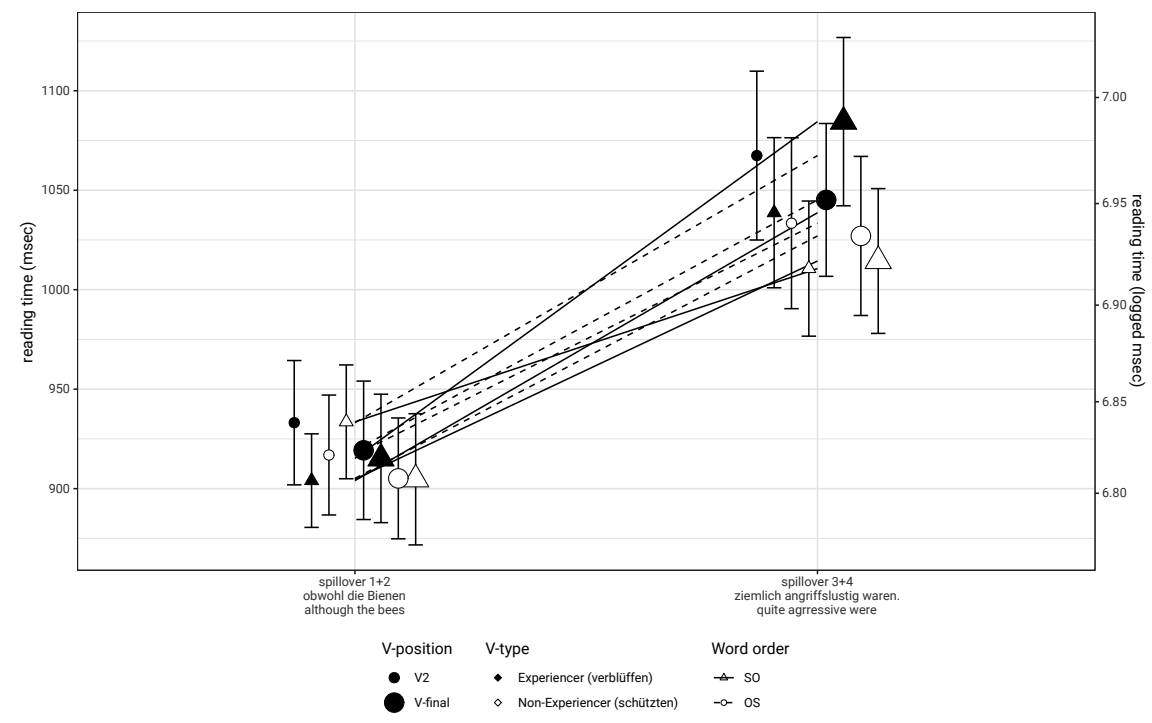

Figure 6.9: Mean reading times for the summarized regions of the spillover are in Experiment 5 (95\% Cls) 


\subsection{Interim discussion}

On the first DP, we found only a categorial contrast between the auxiliaries and longer reading times for the lexical verbs. This effect is present on subjects and objects alike. We assume that this is most likely a spillover effect from the preceding segment, the V2-position, reflecting differences of the initial processing such as lexical access, due to length and frequency. On the high adverb letztens, the NON-EXPERIENCER-SO condition shows prolonged reading times in comparison to the other conditions. This indicates that, in this condition, some additional or demanding process is initiated. Two possibilities come to our mind: First, the subject is incrementally integrated into the parse and some incongruity or implausibility triggers prolonged reading times. Second, the finite verb is reconstructed with the encounter of the subject, as it would be the case for intransitive verbs, and the prolonged reading times are a reflection of the initiated interpretation process. However, visual inspection of individual items did not support either of this hypothesis. Therefore, we must leave open what the reason for this effect is. On the second DP, we found longer reading times for the non-canonical OS order across verb types. However, the strength of this reading time difference was modulated as a function of the verb in the V2-position. The baseline group with the auxiliary in the V2-position showed a robust reading time difference between SO and OS order. This difference is approximately twice as large in the EXPERIENCER-V2 condition whereas, in the NON-EXPERIENCER-V2 condition, it is smaller than in the baseline condition. This modulation indicates that the different verb classes interact with the word order which must reflect verb-related processing. Interestingly, the modulation seems to affect the slow-down of OS and the speed-up of SO uniformly, i. e. for all verb classes the two orders seem to be distanced from a potential zero value, see Figure 6.7. On the low adverb total, we found longer reading times of the NONEXPERIENCER-SO in comparison to the respective V-FINAL baseline condition. This effect looks similar to the one that appeared on the high adverb. Moreover, this penalty for the NON-EXPERIENCER-SO condition continues into the first summarized spillover region but reverses in the final spillover region. At the clause-final verb, we found effects of verb type and word order. This matches the predictions for anticipatory assignment of thematic roles in that it probably reflects a reranking of the thematic roles after the lexical verb was encountered. In the spillover region, we found that, in the V2 condition, the penalty for the NON-EXPERIENCERSO continues on the first two spillover segments, which we also interpret as a reflection of a thematic reranking process. On the two final segments, the factors V-TYPE and WORD ORDER affect the reading times uniformly, which we assume to reflect discourse integration costs, which are higher for experiencer verbs and non-canonical object $<$ subject order. In the V-FINAL condition, on the hand, no ef- 
fect turned up on the first two spillover segments, indicating that the thematic reranking is completed on the clause-final verb. Only on the last two segments, we find again an interaction of V-TYPE and WORD ORDER. We assume that this interaction also reflects discourse integration, like in the V2 condition. However, we must leave open why the SO order seems to be dispreferred in the V-FINAL condition only.

\subsubsection{Agentive controls}

A graphical summary of the main clause segments of the AGENTIVE controls and the $\mathrm{SO}$ subset of the experimental items is given in Figure 6.10.10 The analysis of the AGENTIVE controls revealed only one significant contrast: On the DP1-segment, which was always the subject, we found a simple effect of V-Position with longer reading times for the $\mathrm{V} 2$ condition. This was confirmed by a combined analysis of the DP1-segment for the AGENTIVE controls and the SO subset of the experimental items, which revealed a significant contrast for V-Position with longer reading times for the $\mathrm{V} 2$ condition $(t=3.3680)$ that remains significant across verb types, see Table 6.40 .

Like in previous analysis, we aggregated the reading times for the spillover segments $1+2$, and 2+3, as shown in Figure 6.11. The analysis of the spillover regions did not reveal any new contrast in addition to the primary analysis above. Generally, the AGENTIVE controls pattern with the EXPERIENCER verbs. No contrast to the experimental conditions reaches significance, see Tables 6.41 to 6.42 .

\subsection{Interim discussion}

The comparison with the AGENTIVE controls strengthened the assumption that the V-Position effect on the DP1-segment is a general contrast of auxiliaries and lexical verbs and not verb-type-specific. Furthermore, the comparison with the corresponding conditions of the experimental items did not yield any significant contrasts which indicates that the non-prototypical animacy properties of the arguments of the experimental items did not induce serious differences in reading times.

10 Note that the content of the respective segments of the experimental items and the AGENTIVE controls are not identical and therefore contain length differences, especially the larger segments such as DP1 and DP2. These differences are accounted for in the statistical analysis. Note also that the V-FINAL Condition of the EXPERIENCER Condition and the NON-EXPERIENCER Condition are identical until the final segment of this plot. They are represented by two different points for technical reasons. 


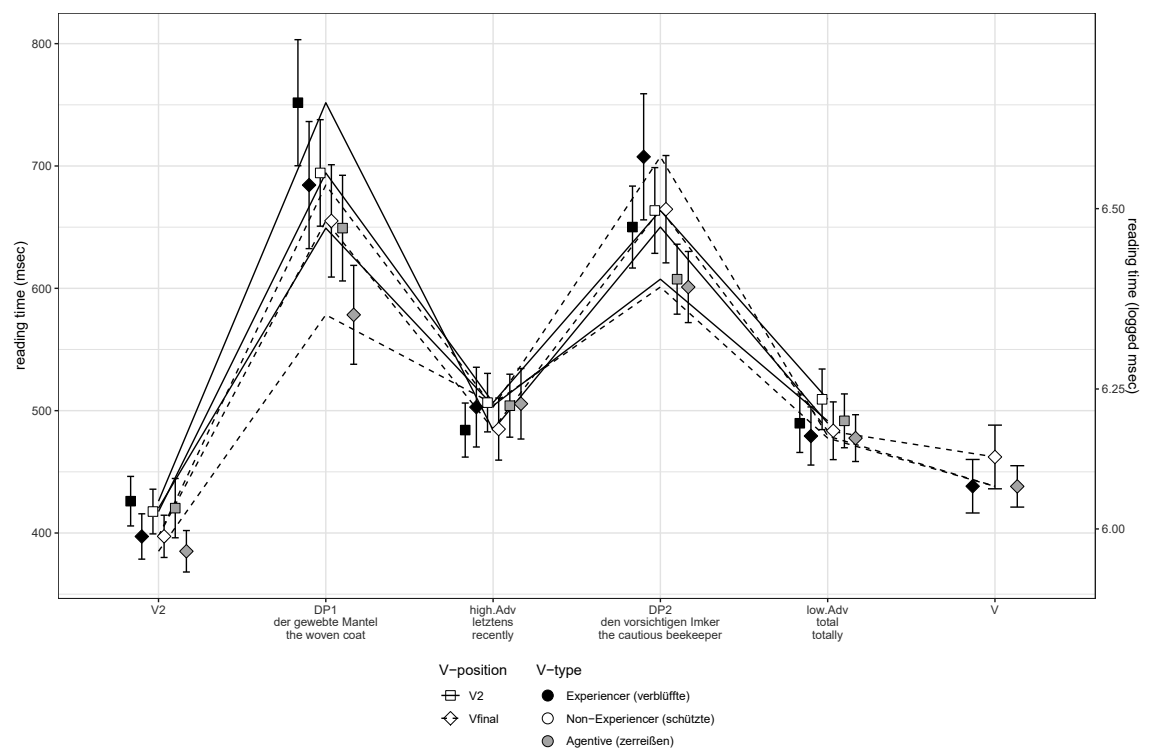

Figure 6.10: Mean reading times of the main clause segments for the experimental items of Experiment 5 and the AGENTIVE controls in the SO order only (95\% Cls)

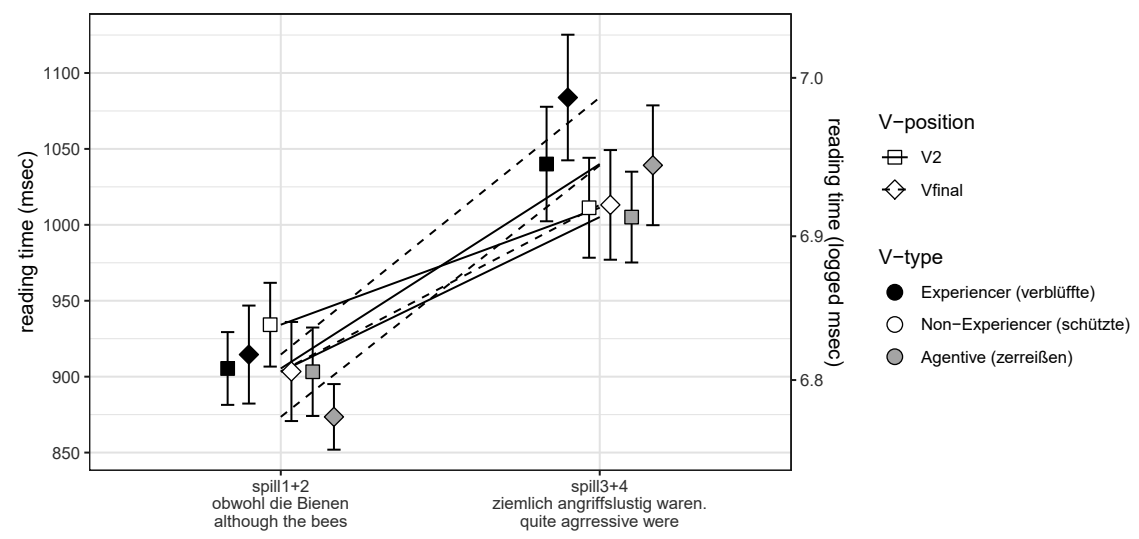

Figure 6.11: Mean reading times for the summed spillover regions of Experiment 5 with the AgENTIVE controls (95\% Cls) 


\subsubsection{Configurational controls}

The reading times of the CONFIGURATIONAL controls are graphically summarized in Figure 6.12. The statistical analysis revealed the following effects: On the DP1segment, we found two main effects with shorter reading times for the V-FINAL condition $(t=-2.3378)$ and the SO condition $(t=-3.2434)$, see Table 6.43. On the high adverb damals, the V2-OS condition showed significantly shorter reading times than the V-FINAL-OS condition $(t=2.7019)$ and the V2-SO condition $(t=2.8287)$, see Table 6.44. On the DP2-segment, the analysis revealed a main effect of V-Position with longer reading times for the V-FINAL condition $(t=3.8157)$, see Table 6.45. No effects could be detected on the low adverb vollständig or on the clause-final participle umgeben. On the spillover segment 1 damit, we detected a main effect of V-Position ( $t=-3.1641)$ with longer reading times for the V2 condition, see Table 6.46. On the spillover segment 2 die Ernte, the analysis revealed a significant contrast between the V2-SO condition and the V-FINAL-SO condition $(t=2.2100)$ with longer reading times for the latter. Additionally, the model also yielded a significant interaction $(t=-2.5702)$, indicating that in the V2 condition OS showed longer reading times than the SO whereas the opposite holds in the V-FINAL condition, see Table 6.47. No effects could be detected on the remaining two segments.



Figure 6.12: Mean reading times for the CONFIGURATIONAL controls in Experiment 5 ( $95 \%$ Cls)

\subsection{Interim discussion}

On the DP1-segment, we found the same contrast with shorter reading times for the V-FINAL condition which was present for the other verb types above. This further strengthens the assumption that this effect is a spillover effect from the pre- 
ceding segment, which reflects the smaller processing demand for the initial activation of the auxiliary. Additionally, we found shorter reading times for the SO conditions on this segment. However, considering that this effect reached significance only for this verb class, it is likely that this is a definiteness effect. Remember that, only for the CONFIGURATIONAL controls, the arguments differed in definiteness. On the high adverb damals, we found an interaction that shows the profile of an object-first preference only when the lexical verb appeared in the V2-position. This effect appears to be very local. In contrast to the other verb types, we didn't find a reading time difference corresponding to WORD ORDER on the second DP but only a contrast of V-TYPE. Additionally, it is rather unexpected that the V2 conditions show longer reading times. We suspect that the speed-up of the V2 condition on this segment stands in a relation with the relative slow-down on the first spillover segment. Similarly, the interaction on the spillover segment 2 indicates that, in the V-FINAL condition, some main clause related processing is still going on whereas the argument order related aspects are already completed in the V2 condition.

\subsubsection{General discussion}

In line with our predictions, we found a subject-first preference in the V-FINAL baseline condition. This preference manifested itself on the DP2-segment with shorter reading times for the $\mathrm{SO}$ condition and is the signature of the default argument processing. Also in line with the predictions of the V2-Reconstruction Hypothesis, the EXPERIENCER condition patterned with the V-FINAL baseline (except for DP1) and the AGENTIVE controls, as if the arguments are processed by the default routine despite the lexical verb surfaced in the V2-position. Only at the second argument, we found the expected verb-type dependent modulation of the WORD ORDER preference. This is the first segment where the V2-Reconstruction Hypothesis predicts verb-related processing effects to appear because with the encounter of the DP2-segment the reconstruction site of the verb can be postulated. In contrast to our predictions, however, the EXPERIENCER verbs did not reflect an OS preference (experiencer-first) but instead showed a stronger subject-first preference than the V-FINAL baseline and the NON-EXPERIENCER Condition. The NONEXPERIENCER verbs, on the other hand, showed a penalty for the canonical SO order that surfaces after both arguments and extends to the first half of the spillover region. We interpreted the latter effect as a thematic reranking process that is likewise observable at the clause-final participles in the V-FINAL condition. The prolonged reading times on the high adverb, directly following the first argument in the NON-EXPERIENCER-SO condition indicates that a verb-related process may 
start directly after the subject. As for now, it remains unclear, what causes this effect and why it only appears for NON-EXPERIENCER-verbs and neither for the EXPERIENCER verbs nor for the AGENTIVE verbs. A similar indication for a immediate argument structure processing is observable for the CONFIGURATIONAL controls, for which V2-OS shows shorter reading times, maybe reflecting an object-first preference. However, effects for these verb classes have to be interpreted with care because the two arguments also involved a definiteness difference. The profile of these early effects match the predictions of the incremental processing hypothesis and constitutes a problem for the V2-Reconstruction Hypothesis. One possibility: Even under the V2-Reconstruction Hypothesis, we need some routine that keeps track of the incoming material which decides when the finite verb must be reconstructed and the interpretation process will be initiated. The early effects could then be interactions with this monitoring process. As for now, we must leave this issue to further research.

Our experiments reproduced some results of previous studies. Like Scheepers et al. (2000), we found a modulation of the $S<0$-preference involving experiencer object verbs. In contrast to their results, we detected an increase of this preference rather than a mitigation. However, our study used only unambiguously marked arguments which could influence the anticipatory assignment of thematic roles, as could the fact that our material involved an animacy contrast. Furthermore, Scheepers et al. (2000) found the mitigation effect in late eye tracking measures. Therefore the correlates of their effect might have to be searched in the spillover region. Although we detected some residuals of verb-argument processing in the spillover region, the effects are not uniform for V2 and V-FINAL sentences and thus not straightforwardly identifiable. A further contrast that may influence the timing of the results is that Scheepers et al. (2000) contrasted main clauses with embedded clauses whereas we contrasted only main clauses but with different verb forms. In relation to Temme \& Verhoeven (2016), it seems that the experiencer-first preference may only be reflected in higher order processing routines related to the discourse structure which might be indicated towards the end of the spillover region. At least in the final region of the EXPERIENCER-V-FINAL condition, an OS-preference showed up. This indicates that the experiencer-first preference might not originate from structural properties but relates to higher order semantico-pragmatic aspects. ${ }^{11}$

In sum, the results of this experiment support the main predictions of the V2Reconstruction Hypothesis. However, we also identified an effect that appeared

11 This assumption is restricted to accusative experiencer objects. Datives experiencers are certainly different and may be structurally exceptional too. 
earlier than expected. Clearly, follow-up studies are in need to provided a more detailed picture of the processing routines in relation to the thematic structure.

Table 6.27: Output of the LME model for DP1-segment in Experiment 5

$\operatorname{lmer}(\log . \mathrm{RT} \sim \mathrm{V} 2$. verb*word. order+segment. length+trial+

(1+segment. length+trial|participant. ID)+(1+word.order|stimulus. ID))

\begin{tabular}{lrrrrrr}
\hline & \multicolumn{3}{c}{ criticized model } & \multicolumn{3}{c}{ raw model } \\
\cline { 2 - 7 } & Estimate & \multicolumn{1}{c}{ SE } & $\mathrm{t}$ & Estimate & SE & $\mathrm{t}$ \\
\hline Intercept (AUXILIARY SO) & 5.7785 & 0.0975 & 59.2692 & 5.8477 & 0.1054 & 55.4920 \\
V2.VERB (EXPERIENCER) & 0.1126 & 0.0300 & 3.7550 & 0.1210 & 0.0337 & 3.5948 \\
V2.VERB (NON-EXPERIENCER) & 0.0739 & 0.0297 & 2.4896 & 0.0676 & 0.0336 & 2.0129 \\
WORD ORDER (OS) & 0.0294 & 0.0303 & 0.9696 & 0.0312 & 0.0331 & 0.9416 \\
Segment length & 0.0262 & 0.0042 & 6.2237 & 0.0234 & 0.0047 & 4.9997 \\
trial & 0.0000 & 0.0008 & -0.0023 & -0.0003 & 0.0008 & -0.3744 \\
EXPERIENCER:OS & -0.0027 & 0.0426 & -0.0636 & -0.0172 & 0.0479 & -0.3587 \\
NON-EXPERIENCER:OS & -0.0012 & 0.0421 & -0.0293 & 0.0086 & 0.0475 & 0.1805 \\
\hline
\end{tabular}

Table 6.28: Output of the LME model for high adverb letztens in Experiment 5

$\operatorname{lmer}(\log . \mathrm{RT} \sim \mathrm{V} 2$. verb*word. order+segment. length+trial+

$(1+$ word.order+trial|participant.ID)+(1|stimulus. ID))

\begin{tabular}{lrrrrrr}
\hline & \multicolumn{3}{c}{ criticized model } & \multicolumn{3}{c}{ raw model } \\
\cline { 2 - 7 } & Estimate & \multicolumn{1}{c}{ SE } & $\mathrm{t}$ & Estimate & SE & $\mathrm{t}$ \\
\hline Intercept (EXPERIENCER SO) & 6.1446 & 0.0670 & 91.6861 & 6.1473 & 0.0723 & 85.0240 \\
V2.VERB (AUXILIARY) & -0.0029 & 0.0179 & -0.1637 & 0.0032 & 0.0226 & 0.1424 \\
V2.VERB (NON-EXPERIENCER) & 0.0412 & 0.0204 & 2.0207 & 0.0452 & 0.0259 & 1.7475 \\
WORD ORDER (OS) & 0.0186 & 0.0244 & 0.7602 & 0.0198 & 0.0287 & 0.6892 \\
Segment length & -0.0029 & 0.0098 & -0.2964 & -0.0009 & 0.0105 & -0.0818 \\
trial & -0.0026 & 0.0004 & -6.5404 & -0.0031 & 0.0005 & -5.9256 \\
AUXILIARY:OS & 0.0169 & 0.0256 & 0.6608 & 0.0200 & 0.0322 & 0.6200 \\
NON-EXPERIENCER:OS & -0.0635 & 0.0293 & -2.1677 & -0.0602 & 0.0370 & -1.6263 \\
\hline
\end{tabular}


Table 6.29: Output of the LME model for DP2-segment in Experiment 5

Imer (log. RT V2. verb*word. order+segment. length+trial+

(1+segment. length+trial|participant. ID)+(1|stimulus. ID))

\begin{tabular}{lrrrrrr}
\hline & \multicolumn{3}{c}{ criticized model } & \multicolumn{3}{c}{ raw model } \\
\cline { 2 - 7 } & Estimate & \multicolumn{1}{c}{ SE } & \multicolumn{1}{c}{$\mathrm{t}$} & Estimate & \multicolumn{1}{c}{ SE } & \multicolumn{1}{c}{$\mathrm{t}$} \\
\hline Intercept (EXPERIENCER SO) & 5.8360 & 0.0699 & 83.4730 & 5.8697 & 0.0802 & 73.1514 \\
V2.VERB (NON-EXPERIENCER) & 0.0358 & 0.0284 & 1.2620 & 0.0230 & 0.0333 & 0.6909 \\
V2.VERB (AUXILIARY) & 0.0197 & 0.0248 & 0.7945 & 0.0374 & 0.0291 & 1.2851 \\
WORD ORDER (OS) & 0.1312 & 0.0290 & 4.5269 & 0.1218 & 0.0340 & 3.5815 \\
Segment length & 0.0243 & 0.0033 & 7.4820 & 0.0230 & 0.0035 & 6.4936 \\
trial & -0.0022 & 0.0007 & -3.1249 & -0.0022 & 0.0007 & -3.2238 \\
AUXILIARY:OS & -0.0773 & 0.0407 & -1.9004 & -0.0603 & 0.0477 & -1.2655 \\
NON-EXPERIENCER:OS & -0.0467 & 0.0354 & -1.3187 & -0.0654 & 0.0415 & -1.5739 \\
\hline
\end{tabular}

Table 6.30: Output of the LME model for the low adverb total in Experiment 5 lmer (log. RT V2. verb*word.order+segment. length+trial+(1+trial|participant. ID)+ (1+word.order|stimulus. ID))

\begin{tabular}{lrrrrrr}
\hline & \multicolumn{3}{c}{ criticized model } & \multicolumn{3}{c}{ raw model } \\
\cline { 2 - 8 } & Estimate & \multicolumn{1}{c}{$\mathrm{SE}$} & \multicolumn{1}{c}{$\mathrm{t}$} & Estimate & $\mathrm{SE}$ & \multicolumn{1}{c}{$\mathrm{t}$} \\
\hline Intercept (NON-EXPERIENCER SO) & 6.0754 & 0.0330 & 184.1343 & 6.1037 & 0.0379 & 161.1473 \\
V2.VERB (AUXILIARY) & -0.0348 & 0.0166 & -2.1027 & -0.0476 & 0.0209 & -2.2758 \\
V2.VERB (EXPERIENCER) & -0.0321 & 0.0189 & -1.7035 & -0.0386 & 0.0238 & -1.6226 \\
WORD ORDER (OS) & -0.0080 & 0.0224 & -0.3594 & -0.0137 & 0.0279 & -0.4903 \\
Segment length & 0.0113 & 0.0024 & 4.6134 & 0.0109 & 0.0030 & 3.6628 \\
trial & -0.0031 & 0.0004 & -7.2363 & -0.0030 & 0.0006 & -5.2831 \\
AUXILIARY:OS & 0.0255 & 0.0232 & 1.1005 & 0.0412 & 0.0293 & 1.4049 \\
EXPERIENCER:OS & 0.0038 & 0.0269 & 0.1424 & 0.0101 & 0.0340 & 0.2965 \\
\hline
\end{tabular}

Table 6.31: Output of the LME model for DP2-segment in the V-FINAL condition in Experiment 5 Imer (log. RT word. order+segment. length+trial+(1 | participant. ID)+(1|stimulus. ID))

\begin{tabular}{lrrrrrrr}
\hline & \multicolumn{3}{c}{ criticized model } & \multicolumn{4}{c}{ raw model } \\
\cline { 2 - 8 } & Estimate & \multicolumn{1}{c}{ SE } & $\mathrm{t}$ & Estimate & SE & \multicolumn{1}{c}{$\mathrm{t}$} \\
\hline Intercept (SO) & 5.8881 & 0.0994 & 59.2222 & 5.9624 & 0.1094 & 54.5052 \\
WORD ORDER (OS) & 0.0679 & 0.0222 & 3.0534 & 0.0487 & 0.0255 & 1.9065 \\
segment length & 0.0233 & 0.0039 & 5.9571 & 0.0205 & 0.0044 & 4.6460 \\
trial & -0.0019 & 0.0006 & -3.0726 & -0.0021 & 0.0007 & -2.8609 \\
\hline
\end{tabular}


Table 6.32: Output of the LME model for clause-final verb in Experiment 5 lmer (log. RT verb. type+word. order+segment. length+trial+ (1+segment. length/participant. ID $)+(1 \mid$ stimulus. ID $))$

\begin{tabular}{lrrrrrr}
\hline & \multicolumn{3}{c}{ criticized model } & \multicolumn{3}{c}{ raw model } \\
\cline { 2 - 7 } & Estimate & \multicolumn{1}{c}{$\mathrm{SE}$} & \multicolumn{1}{c}{$\mathrm{t}$} & Estimate & \multicolumn{1}{c}{$\mathrm{SE}$} & \multicolumn{1}{c}{$\mathrm{t}$} \\
\hline Intercept (EXPERIENCER SO) & 6.0326 & 0.0583 & 103.5089 & 5.9586 & 0.0721 & 82.6040 \\
V-TYPE (NON-EXPERIENCER) & 0.0388 & 0.0190 & 2.0361 & 0.0531 & 0.0237 & 2.2407 \\
WORD ORDER (OS) & 0.0437 & 0.0187 & 2.3428 & 0.0342 & 0.0234 & 1.4627 \\
Segment length & -0.0023 & 0.0052 & -0.4377 & 0.0066 & 0.0070 & 0.9429 \\
trial & -0.0021 & 0.0004 & -5.6392 & -0.0025 & 0.0005 & -5.2200 \\
V-TYPE:WORD ORDER & -0.0292 & 0.0271 & -1.0789 & -0.0214 & 0.0340 & -0.6315 \\
\hline
\end{tabular}

Table 6.33: Output of the LME model for spillover segment 1 obwohl of the V2-subgroup in Experiment 5

Imer (log. RT verb. type*word . order+segment. length+trial+ $(1+$ segment. length+trial |participant. ID $)+(1 \mid$ stimulus. ID $))$

\begin{tabular}{lrrrrrr}
\hline & \multicolumn{3}{c}{ criticized model } & \multicolumn{3}{c}{ raw model } \\
\cline { 2 - 7 } & Estimate & \multicolumn{1}{c}{ SE } & \multicolumn{1}{c}{$\mathrm{t}$} & Estimate & \multicolumn{1}{c}{ SE } & \multicolumn{1}{c}{$\mathrm{t}$} \\
\hline Intercept (EXPERIENCER SO) & 5.9718 & 0.0412 & 145.0120 & 5.9511 & 0.0446 & 133.3687 \\
V-TYPE (NON-EXPERIENCER) & 0.0310 & 0.0159 & 1.9461 & 0.0371 & 0.0191 & 1.9457 \\
WORD ORDER (OS) & 0.0103 & 0.0162 & 0.6375 & 0.0273 & 0.0193 & 1.4133 \\
Segment length & 0.0095 & 0.0059 & 1.6200 & 0.0130 & 0.0064 & 2.0135 \\
trial & -0.0013 & 0.0004 & -3.1935 & -0.0014 & 0.0005 & -2.8916 \\
NON-EXPERIENCER:OS & -0.0232 & 0.0228 & -1.0188 & -0.0289 & 0.0271 & -1.0645 \\
\hline
\end{tabular}

Table 6.34: Output of the LME model for spillover segment 2 die Bienen of the V2-subgroup in Experiment 5

Imer (log. RT verb. type*word. order+segment. length+trial+ (1+segment. length/participant. ID $)+(1 \mid$ stimulus. ID $))$

\begin{tabular}{lrrrrrr}
\hline & \multicolumn{3}{c}{ criticized model } & \multicolumn{3}{c}{ raw model } \\
\cline { 2 - 7 } & Estimate & \multicolumn{1}{c}{$\mathrm{SE}$} & \multicolumn{1}{c}{$\mathrm{t}$} & Estimate & \multicolumn{1}{c}{$\mathrm{SE}$} & \multicolumn{1}{c}{$\mathrm{t}$} \\
\hline Intercept (EXPERIENCER SO) & 5.9718 & 0.0412 & 145.0120 & 5.9511 & 0.0446 & 133.3687 \\
V-TYPE (NON-EXPERIENCER) & 0.0310 & 0.0159 & 1.9461 & 0.0371 & 0.0191 & 1.9457 \\
WORD ORDER (OS) & 0.0103 & 0.0162 & 0.6375 & 0.0273 & 0.0193 & 1.4133 \\
Segment length & 0.0095 & 0.0059 & 1.6200 & 0.0130 & 0.0064 & 2.0135 \\
trial & -0.0013 & 0.0004 & -3.1935 & -0.0014 & 0.0005 & -2.8916 \\
NON-EXPERIENCER:OS & -0.0232 & 0.0228 & -1.0188 & -0.0289 & 0.0271 & -1.0645 \\
\hline
\end{tabular}


Table 6.35: Output of the LME model for spillover segment 4 waren of the V2-subgroup in Experiment 5

lmer (log. RT verb. type*word. order+segment. length+trial+

(1+segment. length+trial|participant. ID)+(1|stimulus. ID))

\begin{tabular}{lrrrrrr}
\hline & \multicolumn{3}{c}{ criticized model } & \multicolumn{3}{c}{ raw model } \\
\cline { 2 - 7 } & Estimate & \multicolumn{1}{c}{ SE } & \multicolumn{1}{c}{$\mathrm{t}$} & Estimate & SE & \multicolumn{1}{c}{$\mathrm{t}$} \\
\hline Intercept (EXPERIENCER OS) & 6.0971 & 0.0388 & 157.1231 & 6.0962 & 0.0433 & 140.8018 \\
V-TYPE (NON-EXPERIENCER) & -0.0522 & 0.0216 & -2.4194 & -0.0383 & 0.0257 & -1.4928 \\
WORD ORDER (SO) & -0.0502 & 0.0212 & -2.3665 & -0.0365 & 0.0254 & -1.4393 \\
Segment length & 0.0096 & 0.0027 & 3.5166 & 0.0105 & 0.0029 & 3.5912 \\
trial & -0.0033 & 0.0006 & -5.3642 & -0.0031 & 0.0006 & -4.9109 \\
NON-EXPERIENCER:SO & 0.0418 & 0.0298 & 1.4009 & 0.0135 & 0.0356 & 0.3782 \\
\hline
\end{tabular}

Table 6.36: Output of the LME model for spillover segment 4 waren of the V-FINAL-subgroup in Experiment 5

lmer(log.RT verb. type*word .order+segment. length+trial+(1+trial|participant. ID)+ (1|stimulus. ID))

\begin{tabular}{lrrrrrr}
\hline & \multicolumn{3}{c}{ criticized model } & \multicolumn{3}{c}{ raw model } \\
\cline { 2 - 7 } & Estimate & \multicolumn{1}{c}{ SE } & \multicolumn{1}{c}{$\mathrm{t}$} & Estimate & SE & \multicolumn{1}{c}{$\mathrm{t}$} \\
\hline Intercept (EXPERIENCER SO) & 6.1101 & 0.0484 & 126.1970 & 6.1389 & 0.0511 & 120.1603 \\
V-TYPE (NON-EXPERIENCER) & -0.0518 & 0.0243 & -2.1268 & -0.0679 & 0.0290 & -2.3380 \\
WORD ORDER (OS) & -0.0030 & 0.0240 & -0.1238 & -0.0332 & 0.0284 & -1.1695 \\
Segment length & 0.0071 & 0.0024 & 2.9559 & 0.0063 & 0.0027 & 2.3290 \\
trial & -0.0021 & 0.0007 & -3.1663 & -0.0020 & 0.0008 & -2.5204 \\
NON-EXPERIENCER:OS & 0.0149 & 0.0341 & 0.4363 & 0.0623 & 0.0405 & 1.5365 \\
\hline
\end{tabular}

Table 6.37: Output of the LME model for spillover segment 1+2 obwohl die Bienen of the V2subgroup in Experiment 5

lmer (log. RT verb. type*word. order+segment. length+trial+

(1+segment. length+trial|participant. ID)+(1|stimulus. ID))

\begin{tabular}{lrrrrrr}
\hline & \multicolumn{3}{c}{ criticized model } & \multicolumn{3}{c}{ raw model } \\
\cline { 2 - 7 } & Estimate & \multicolumn{1}{c}{$\mathrm{SE}$} & \multicolumn{1}{c}{$\mathrm{t}$} & Estimate & \multicolumn{1}{c}{$\mathrm{SE}$} & \multicolumn{1}{c}{$\mathrm{t}$} \\
\hline Intercept (EXPERIENCER SO) & 6.6258 & 0.0566 & 117.0060 & 6.6388 & 0.0602 & 110.3324 \\
V-TYPE (NON-EXPERIENCER) & 0.0264 & 0.0155 & 1.7041 & 0.0322 & 0.0176 & 1.8280 \\
WORD ORDER (OS) & 0.0252 & 0.0156 & 1.6190 & 0.0291 & 0.0177 & 1.6411 \\
Segment length & 0.0079 & 0.0031 & 2.5330 & 0.0075 & 0.0033 & 2.2926 \\
trial & -0.0016 & 0.0004 & -4.0063 & -0.0015 & 0.0004 & -3.5846 \\
NON-EXPERIENCER:OS & -0.0442 & 0.0220 & -2.0100 & -0.0512 & 0.0249 & -2.0528 \\
\hline
\end{tabular}


Table 6.38: Output of the LME model for spillover segment 3+4 ziemlich angriffslustig waren of the V2-subgroup in Experiment 5

lmer (log. RT verb. type+word.order+segment . length+trial+

(1+segment. length+trial|participant. ID)+(1|stimulus. ID))

\begin{tabular}{lrrrrrr}
\hline & \multicolumn{3}{c}{ criticized model } & \multicolumn{3}{c}{ raw model } \\
\cline { 2 - 7 } & Estimate & \multicolumn{1}{c}{ SE } & \multicolumn{1}{c}{$\mathrm{t}$} & Estimate & \multicolumn{1}{c}{ SE } & \multicolumn{1}{c}{$\mathrm{t}$} \\
\hline Intercept (NON-EXPERIENCER SO) & 6.5867 & 0.0607 & 108.5453 & 6.5806 & 0.0668 & 98.5427 \\
V-TYPE (EXPERIENCER) & 0.0418 & 0.0125 & 3.3371 & 0.0376 & 0.0150 & 2.5013 \\
WORD ORDER (OS) & 0.0255 & 0.0123 & 2.0726 & 0.0251 & 0.0148 & 1.6909 \\
Segment length & 0.0094 & 0.0017 & 5.6427 & 0.0101 & 0.0019 & 5.3069 \\
trial & -0.0026 & 0.0006 & -4.7164 & -0.0026 & 0.0006 & -4.3485 \\
\hline
\end{tabular}

Table 6.39: Output of the LME model for spillover segment 3+4 ziemlich angriffslustig waren of the V-FINAL-subgroup in Experiment 5

lmer (log. RT verb. type*word.order+segment. length+trial+

(1+segment. length+trial|participant. ID)+(1|stimulus. ID))

\begin{tabular}{lrrrrrr}
\hline & \multicolumn{3}{c}{ criticized model } & \multicolumn{3}{c}{ raw model } \\
\cline { 2 - 7 } & Estimate & \multicolumn{1}{c}{ SE } & \multicolumn{1}{c}{$\mathrm{t}$} & Estimate & \multicolumn{1}{c}{ SE } & $\mathrm{t}$ \\
\hline Intercept (NON-EXPERIENCER SO) & 6.5969 & 0.0611 & 107.8891 & 6.6318 & 0.0644 & 103.0088 \\
V-TYPE (EXPERIENCER) & 0.0708 & 0.0182 & 3.8937 & 0.0669 & 0.0216 & 3.1030 \\
WORD ORDER (OS) & 0.0205 & 0.0181 & 1.1335 & 0.0090 & 0.0216 & 0.4146 \\
Segment length & 0.0090 & 0.0017 & 5.3134 & 0.0085 & 0.0018 & 4.6829 \\
trial & -0.0024 & 0.0006 & -4.1899 & -0.0024 & 0.0006 & -3.9285 \\
EXPERIENCER:OS & -0.0437 & 0.0254 & -1.7192 & -0.0403 & 0.0302 & -1.3333 \\
\hline
\end{tabular}

Table 6.40: Output of the LME model for the DP1-segment with the AGENTIVE controls in Experiment 5

$\operatorname{lmer}(\log$. RT verb. type*verb. position+segment. length+trial+(1+trial|participant. ID)+ (1|stimulus. ID))

\begin{tabular}{lrrrrrr}
\hline & \multicolumn{3}{c}{ criticized model } & \multicolumn{3}{c}{ raw model } \\
\cline { 2 - 7 } & Estimate & \multicolumn{1}{c}{$\mathrm{SE}$} & $\mathrm{t}$ & Estimate & \multicolumn{1}{c}{$\mathrm{SE}$} & $\mathrm{t}$ \\
\hline Intercept (AGENTIVE V-FINAL) & 5.6993 & 0.1036 & 55.0359 & 5.7177 & 0.0992 & 57.6183 \\
V-TYPE (EXPERIENCER) & 0.0758 & 0.0460 & 1.6487 & 0.0568 & 0.0514 & 1.1062 \\
V-TYPE (NON-EXPERIENCER) & 0.0603 & 0.0463 & 1.3004 & 0.0471 & 0.0519 & 0.9072 \\
V-POSITION (V2) & 0.1058 & 0.0314 & 3.3680 & 0.0999 & 0.0363 & 2.7484 \\
Segment length & 0.0271 & 0.0049 & 5.5694 & 0.0270 & 0.0055 & 4.8951 \\
trial & -0.0003 & 0.0007 & -0.4045 & -0.0003 & 0.0008 & -0.3403 \\
EXPERIENCER:V2 & -0.0178 & 0.0453 & -0.3926 & 0.0215 & 0.0523 & 0.4118 \\
NON-EXPERIENCER:V2 & -0.0318 & 0.0454 & -0.7005 & -0.0298 & 0.0528 & -0.5652 \\
\hline
\end{tabular}


Table 6.41: Output of the LME model for spillover segment 1+2 with the AGENTIVE controls in Experiment 5

Imer (log.RT verb. type*verb. position+segment. length+trial+

(1+segment. length+trial|participant. ID)+(1|stimulus. ID))

\begin{tabular}{lrrrrrr}
\hline & \multicolumn{3}{c}{ criticized model } & \multicolumn{3}{c}{ raw model } \\
\cline { 2 - 7 } & Estimate & \multicolumn{1}{c}{ SE } & \multicolumn{1}{c}{$\mathrm{t}$} & Estimate & \multicolumn{1}{c}{ SE } & \multicolumn{1}{c}{$\mathrm{t}$} \\
\hline Intercept (NON-EXPERIENCER V2) & 6.6408 & 0.0501 & 132.5052 & 6.6687 & 0.0529 & 126.1178 \\
V-TYPE (AGENTIVE) & -0.0303 & 0.0218 & -1.3880 & -0.0269 & 0.0232 & -1.1581 \\
V-TYPE (EXPERIENCER) & -0.0362 & 0.0155 & -2.3370 & -0.0343 & 0.0181 & -1.8881 \\
V-POSITION (V-FINAL) & -0.0513 & 0.0157 & -3.2578 & -0.0428 & 0.0183 & -2.3327 \\
Segment length & 0.0087 & 0.0025 & 3.5065 & 0.0077 & 0.0027 & 2.8311 \\
trial & -0.0018 & 0.0004 & -4.9448 & -0.0015 & 0.0004 & -3.8620 \\
AGENTIVE:V-FINAL & 0.0357 & 0.0217 & 1.6429 & 0.0135 & 0.0253 & 0.5343 \\
EXPERIENCER:V-FINAL & 0.0505 & 0.0222 & 2.2748 & 0.0501 & 0.0259 & 1.9332 \\
\hline
\end{tabular}

Table 6.42: Output of the LME model for the region consisting of spillover segment $3+4$ with the AGENTIVE controls in Experiment 5

Imer (log. RT verb. type*verb. position+segment. length+trial+(1+trial|participant. ID)+ (1|stimulus. ID))

\begin{tabular}{lrrrrrr}
\hline & \multicolumn{3}{c}{ criticized model } & \multicolumn{3}{c}{ raw model } \\
\cline { 2 - 7 } & Estimate & \multicolumn{1}{c}{$\mathrm{SE}$} & \multicolumn{1}{c}{$\mathrm{t}$} & Estimate & \multicolumn{1}{c}{$\mathrm{SE}$} & \multicolumn{1}{c}{$\mathrm{t}$} \\
\hline Intercept (EXPERIENCER V-FINAL) & 6.6105 & 0.0548 & 120.6926 & 6.6485 & 0.0561 & 118.4244 \\
V-TYPE (NON-EXPERIENCER) & -0.0736 & 0.0175 & -4.2200 & -0.0680 & 0.0206 & -3.3047 \\
V-TYPE (AGENTIVE) & -0.0353 & 0.0260 & -1.3614 & -0.0397 & 0.0263 & -1.5101 \\
V-POSITION (V2) & -0.0482 & 0.0171 & -2.8266 & -0.0403 & 0.0202 & -1.9946 \\
Segment length & 0.0112 & 0.0015 & 7.6682 & 0.0104 & 0.0015 & 6.8627 \\
trial & -0.0022 & 0.0005 & -4.2187 & -0.0023 & 0.0006 & -4.1039 \\
NON-EXPERIENCER:V2 & 0.0525 & 0.0244 & 2.1508 & 0.0374 & 0.0288 & 1.2961 \\
AGENTIVE:V2 & 0.0267 & 0.0237 & 1.1238 & 0.0192 & 0.0281 & 0.6832 \\
\hline
\end{tabular}

Table 6.43: Output of the LME model for DP1-segment of the CONFIGURATIONAL controls in Experiment 5

lmer (log.RT verb. position+word.order+segment. length+trial+ (1+segment. length+trial|participant. ID)+(1|stimulus. ID))

\begin{tabular}{lrcrrrr}
\hline & \multicolumn{3}{c}{ criticized model } & \multicolumn{3}{c}{ raw model } \\
\cline { 2 - 7 } & Estimate & \multicolumn{1}{c}{ SE } & \multicolumn{1}{c}{$\mathrm{t}$} & Estimate & SE & \multicolumn{1}{c}{$\mathrm{t}$} \\
\hline Intercept (V2 OS) & 5.4138 & 0.3270 & 16.5549 & 5.6271 & 0.3468 & 16.2235 \\
V-POSITION (V-FINAL) & -0.0649 & 0.0278 & -2.3378 & -0.0693 & 0.0305 & -2.2700 \\
WORD ORDER (SO) & -0.0932 & 0.0287 & -3.2434 & -0.0932 & 0.0328 & -2.8407 \\
Segment length & 0.0531 & 0.0190 & 2.8041 & 0.0422 & 0.0203 & 2.0765 \\
trial & -0.0001 & 0.0012 & -0.0918 & -0.0002 & 0.0013 & -0.1512 \\
\hline
\end{tabular}


Table 6.44: Output of the LME model for the high adverb segment of the CONFIGURATIONAL controls in Experiment 5

lmer(log. RT verb. position+word. order+segment. length+trial+(1|participant. ID)+

(1|stimulus. ID))

\begin{tabular}{lrrrrrr}
\hline & \multicolumn{3}{c}{ criticized model } & \multicolumn{3}{c}{ raw model } \\
\cline { 2 - 7 } & Estimate & \multicolumn{1}{c}{$\mathrm{SE}$} & \multicolumn{1}{c}{$\mathrm{t}$} & Estimate & \multicolumn{1}{c}{$\mathrm{SE}$} & \multicolumn{1}{c}{$\mathrm{t}$} \\
\hline Intercept (V2 OS) & 6.0328 & 0.0387 & 156.0507 & 6.0731 & 0.0471 & 129.0500 \\
V-POSITION (V-FINAL) & 0.0695 & 0.0257 & 2.7019 & 0.0762 & 0.0343 & 2.2178 \\
WORD ORDER (SO) & 0.0729 & 0.0258 & 2.8287 & 0.0732 & 0.0344 & 2.1262 \\
Segment length & 0.0058 & 0.0038 & 1.5277 & 0.0022 & 0.0051 & 0.4387 \\
trial & -0.0018 & 0.0005 & -3.4285 & -0.0011 & 0.0007 & -1.6399 \\
V-FINAL:SO & -0.0616 & 0.0366 & -1.6816 & -0.0610 & 0.0487 & -1.2527 \\
\hline
\end{tabular}

Table 6.45: Output of the LME model for DP2-segment of the CONFIGURATIONAL controls in Experiment 5

lmer (log. RT verb. position+word.order+segment. length+trial+(1 | participant. ID)+ (1|stimulus.ID))

\begin{tabular}{lrrrrrr}
\hline & \multicolumn{3}{c}{ criticized model } & \multicolumn{3}{c}{ raw model } \\
\cline { 2 - 7 } & Estimate & \multicolumn{1}{c}{$\mathrm{SE}$} & \multicolumn{1}{c}{$\mathrm{t}$} & Estimate & $\mathrm{SE}$ & \multicolumn{1}{c}{$\mathrm{t}$} \\
\hline Intercept (V2 SO) & 6.4494 & 0.2597 & 24.8315 & 6.1417 & 0.3272 & 18.7707 \\
V-POSITION (V-FINAL) & 0.0874 & 0.0229 & 3.8157 & 0.0673 & 0.0294 & 2.2930 \\
WORD ORDER (OS) & 0.0230 & 0.0245 & 0.9384 & 0.0315 & 0.0315 & 1.0017 \\
segment length & -0.0138 & 0.0146 & -0.9449 & 0.0037 & 0.0185 & 0.2000 \\
trial & -0.0011 & 0.0007 & -1.7069 & -0.0019 & 0.0008 & -2.2551 \\
\hline
\end{tabular}

Table 6.46: Output of the LME model for spillover segment 1 of the CONFIGURATIONAL controls in Experiment 5

lmer (log.RT verb. position+word . order+segment. length+trial+

(1+segment. length+trial|participant. ID)+(1|stimulus. ID))

\begin{tabular}{lrrrrrr}
\hline & \multicolumn{3}{c}{ criticized model } & \multicolumn{3}{c}{ raw model } \\
\cline { 2 - 7 } & Estimate & \multicolumn{1}{c}{ SE } & \multicolumn{1}{c}{$\mathrm{t}$} & Estimate & \multicolumn{1}{c}{ SE } & \multicolumn{1}{c}{$\mathrm{t}$} \\
\hline Intercept (V2 SO) & 5.9005 & 0.0520 & 113.3904 & 5.9042 & 0.0578 & 102.1478 \\
V-POSITION (V-FINAL) & -0.0499 & 0.0158 & -3.1641 & -0.0482 & 0.0190 & -2.5418 \\
WORD ORDER (OS) & 0.0260 & 0.0157 & 1.6510 & 0.0096 & 0.0190 & 0.5060 \\
Segment length & 0.0260 & 0.0064 & 4.0859 & 0.0284 & 0.0071 & 3.9850 \\
trial & -0.0007 & 0.0005 & -1.2844 & -0.0006 & 0.0006 & -0.9003 \\
\hline
\end{tabular}


Table 6.47: Output of the LME model for spillover segment 2 of the CONFIGURATIONAL controls in Experiment 5

$\operatorname{lmer}(\log$. RT verb. position*word. order+segment. length+trial+(1|participant. ID)+

(1|stimulus. ID))

\begin{tabular}{lrrrrrr}
\hline & \multicolumn{3}{c}{ criticized model } & \multicolumn{3}{c}{ raw model } \\
\cline { 2 - 7 } & Estimate & \multicolumn{1}{c}{$\mathrm{SE}$} & $\mathrm{t}$ & Estimate & $\mathrm{SE}$ & \multicolumn{1}{c}{$\mathrm{t}$} \\
\hline Intercept (V2 SO) & 5.8149 & 0.1486 & 39.1347 & 5.7732 & 0.1623 & 35.5796 \\
V-POSITION (V-FINAL) & 0.0564 & 0.0255 & 2.2100 & 0.0548 & 0.0313 & 1.7496 \\
WORD ORDER (OS) & 0.0462 & 0.0255 & 1.8131 & 0.0303 & 0.0313 & 0.9657 \\
Segment length & 0.0197 & 0.0123 & 1.5932 & 0.0241 & 0.0135 & 1.7800 \\
trial & -0.0010 & 0.0005 & -1.8773 & -0.0010 & 0.0006 & -1.5344 \\
V-FINAL:OS & -0.0927 & 0.0361 & -2.5702 & -0.0663 & 0.0443 & -1.4977 \\
\hline
\end{tabular}




\subsection{Summary of the experimental investigations}

In this chapter, I presented four self-paced reading experiments designed to test the prediction of the V2-Reconstruction Hypothesis about the processing of the finite verb in on-line sentence comprehension. Experiment 2 used the verbal NPI brauchen 'need to' whose grammaticality/interpretability hinges on a proper NPIlicensor. The results indicate that the NPI-verb in V2-position triggers prolonged reading times at the potential base position of the finite verb if this position is not in the scope of an NPI-licensor. This matches the predictions of the V2-Reconstruction Hypothesis, namely that the finite verb is automatically reconstructed into potential base positions, comparable to filler-gap parsing. Experiment 3 was a follow-up study designed to diagnose whether the NPI-violation effect of experiment 2 was really tied to the base position of the finite verb, or whether the effect was actually related to the base position of the negation, which was almost adjacent to the one of the verb. Although the results are less pronounced than in experiment 2, they clearly favor the V2-Reconstruction Hypothesis over the alternative hypothesis.

Experiment 4 applied a similar logic as the preceding experiments. Two verb classes were contrasted in the V2-position, which selected bare infinitives and $z u$-infinitives respectively. The first potential reconstruction site followed a $z u$-infinitive. In line with the V2-Reconstruction Hypothesis, the results showed longer reading times for the matrix verb whose selection requirement are not satisfied at this point. This indicates that the finite verb is automatically reconstructed into a potential base position before the selection requirement are evaluated. This was supported by the observation that the selection mismatch effect was directly preceded by another effect, which probably reflects lexical reactivation.

Experiment 5 was intended to tap into the verb-related argument processing by contrasting verb classes with different thematic roles and corresponding argument-order preferences. The main result showed a modulation of the subjectfirst preference as a function of the V2-verb at the position directly preceding the reconstruction site. Additionally, the results also included potential verb-related effects at earlier points which indicate that thematic processing might starts prior to the reconstruction of the finite verb.

In sum, this chapter presented a series of experiments which investigated three properties which depend on the interpretation of the lexical content of a verb in the V2-position and tested whether their processing correlates can be diagnosed at a distant position in the sentence as predicted by the V2-Reconstruction Hypothesis. The expectations have been met for polarity-sensitive properties, which trigger an immediate response to the licensing requirement at the reconstruction site. The predictions could also be confirmed for the evaluation of se- 
lection requirements of the V2-verb, although these seem to be evaluated only shortly after lexical reactivation took place. Concerning the evaluation of thematic structure of the V2-verb, the result are compatible with the V2-Reconstruction Hypothesis. However, the result are less clear-cut than for the other two phenomena. This is not very surprising considering that argument order does not induce strict ungrammaticality but only preferences, which also strongly interact with discourse-properties. Taken together, the experiments showed that the V2-Reconstruction Hypothesis yields very accurate predictions concerning the temporal locus at which the lexical information of the V2-verb is evaluated during the on-line processing of V2-clauses in German. 